\title{
An Experiment Monitoring Signals of Coal Bed Simulation under Forced Vibration Conditions
}

\author{
Chengwu Li, ${ }^{1}$ Po Hu, ${ }^{1}$ Tianbao Gao, ${ }^{2}$ Yingfeng Sun, ${ }^{1}$ Shengyang Shao, ${ }^{1}$ and Qifei Wang ${ }^{1}$ \\ ${ }^{1}$ Faculty of Resources \& Safety Engineering, China University of Mining \& Technology, Beijing, D11 Xuyuan Road, \\ Haidian District, Beijing 100083, China \\ ${ }^{2}$ School of Energy and Safety Engineering, Tianjin Chengjian Uninversity, Tianjin 300384, China \\ Correspondence should be addressed to Po Hu; ngd322hupo@gmail.com
}

Received 7 July 2014; Accepted 29 September 2014

Academic Editor: Caiping Lu

Copyright (C) 2015 Chengwu Li et al. This is an open access article distributed under the Creative Commons Attribution License, which permits unrestricted use, distribution, and reproduction in any medium, provided the original work is properly cited.

\begin{abstract}
An experiment simulating coal seam under forced vibration conditions was conducted. Acceleration response and microseism signal during the experiment were collected and analyzed. It is found that, with an increasing amount of vibration, the natural frequency of the specimen decreases, and this phenomenon reflects fractures appearing in the specimen. Acceleration response signals show that peaks in shock excitation frequency and shock excitation acceleration affect the acceleration response, which reflects damage to the specimen. When shock excitation frequency nears natural frequency, the acceleration response first decreases and then increases. When resonance occurs, it reaches its maximum value. As shock excitation acceleration peaks increase, the acceleration response peak of the specimen also increases. We conclude that destruction is mainly concentrated in the coal seam evidenced by specimen destruction situation. Then shock excitation frequency and shock excitation acceleration influence on microseism signals were analyzed by Hilbert-Huang transform. By receiving these signals and analyzing their characteristics, it is beneficial to develop new methods to predict disasters underground dynamically in the future.
\end{abstract}

\section{Introduction}

An unexpected and violent simultaneous ejection of a large mass of gas and coal from an underground working face during mining is identified as "instantaneous coal outburst" $[1,2]$. This, understandably, is a massive hazard for coal mining workers. To learn and predict outburst accidents, the factors contributing to outburst have been widely studied for decades. A wealth of hypotheses, such as the dynamic model $[1,3-5]$, the pocket model, spherical shell destabilization model [6], and gas phase transformation model [7], have been proposed to explain this phenomena. No single theory, however, can fully explain all the characteristics of outburst, because the phenomenon is so complex. Among these previously reported models, the effects of vibration and its potential to trigger an outburst have not been thoroughly explored. In the mining process, many different activities produce vibration. As previously reported by Zhou and He, 8362 of 8669 outbursts (96.5\%) were related to human activities such as drilling, blast mining, or coal dropping [8]. These activities cause vibration that alter the mechanical properties of coal and reduce coal strength $[7,9]$. To this effect, this paper posits that vibration is a critical factor contributing to instantaneous outburst. Study of vibration characteristics and signals is crucial to a better understanding of outburst phenomena, and, ultimately, the reduction of outburst-related disasters.

Blasting is one process liable to cause outbursts. Millisecond delay blasting, a type of sectional blasting, is the primary method of roadway development in Chinese outburst mines. Every blast produces vibration, each of which forms a $\mathrm{P}$ wave (particle vibration direction is similar to wave propagation) as it moves through space, potentially quite far. In many coal mines, roadways exist horizontally in the coal bed, making the direction of vibration produced by blasting likewise horizontal. Earthquakes also cause horizontal coal bed vibration. In this experiment, the horizontal vibration of the specimen was produced by a vibration table. 
TABLE 1: The vibration table characters.

\begin{tabular}{lccccccc}
\hline Size & Maximum payload & $\begin{array}{c}\text { Maximum } \\
\text { overturn } \\
\text { moment }\end{array}$ & $\begin{array}{c}\text { Maximum } \\
\text { eccentric } \\
\text { torque }\end{array}$ & $\begin{array}{c}\text { Maximum } \\
\text { displacement }\end{array}$ & $\begin{array}{c}\text { Frequency } \\
\text { range }\end{array}$ & $\begin{array}{c}\text { Acceleration } \\
\text { at maximum } \\
\text { load }\end{array}$ & $\begin{array}{c}\text { Maximum } \\
\text { speed }\end{array}$ \\
\hline $3 \mathrm{~m} \times 3 \mathrm{~m}$ & $10000 \mathrm{~kg}$ & $300 \mathrm{KN} \cdot \mathrm{m}$ & $100 \mathrm{KN} \cdot \mathrm{m}$ & $\pm 100 \mathrm{~mm}$ & $0.2 \mathrm{~Hz} \sim 50 \mathrm{~Hz}$ & $1.2 \mathrm{~g}$ & $1.0 \mathrm{~m} / \mathrm{s}$ \\
\hline
\end{tabular}

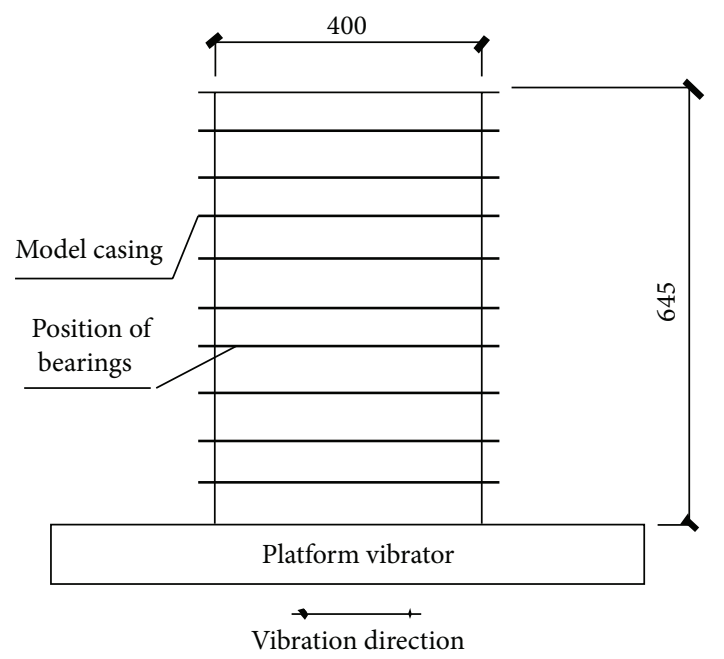

FIGURE 1: Sketch map of forced vibration specimen.

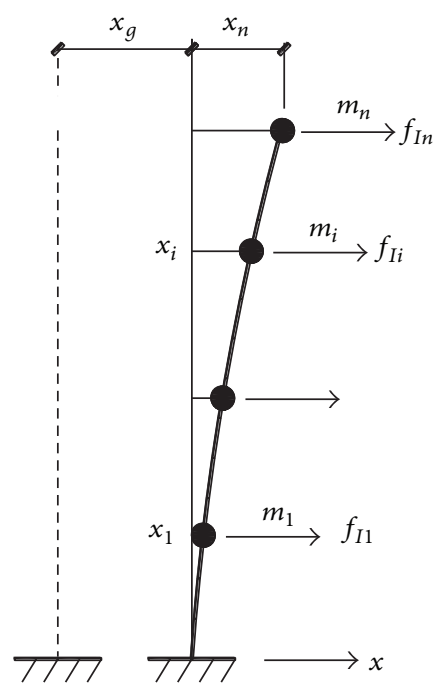

Figure 2: Deformation and force of multiple-degree-of-freedom forced vibration system.

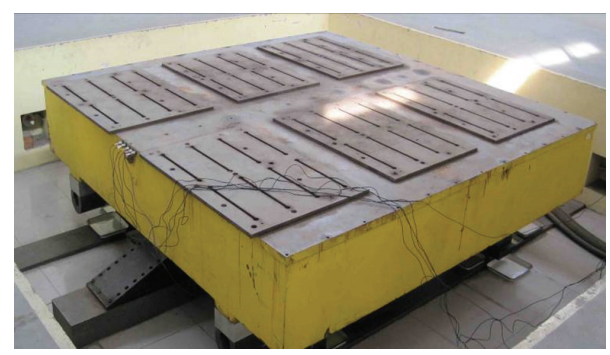

FIGURE 3: Vibrating table.

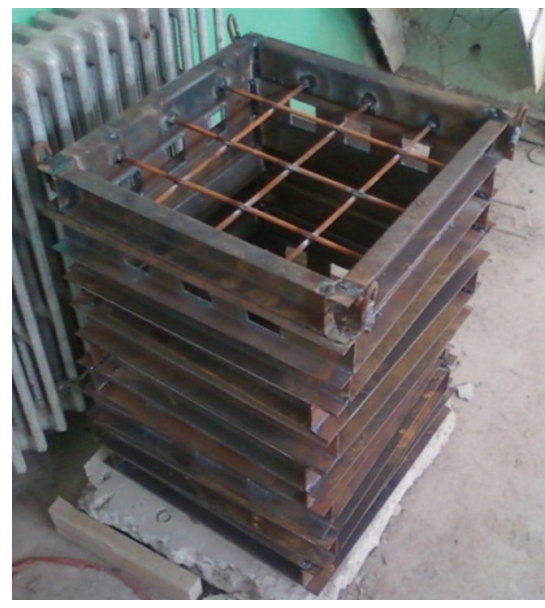

Figure 4: Steel frame of model box.
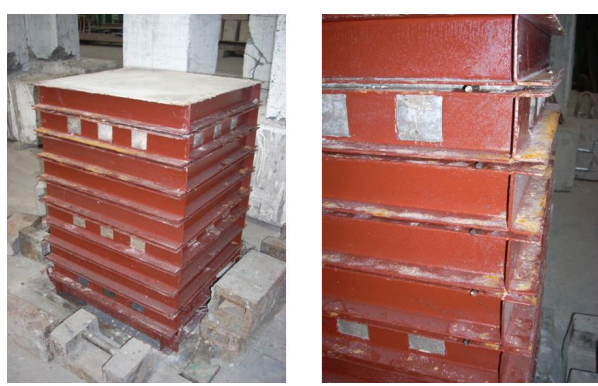

FIgUre 5: Model specimen after completion.

TABLE 2: Material and mixing ratio.

\begin{tabular}{lcccccc}
\hline & Cement & Lime & $\begin{array}{c}\text { Coal } \\
\text { powder }\end{array}$ & $\begin{array}{c}\text { Medium } \\
\text { sand }\end{array}$ & Gravel & Water \\
\hline Coal floor & 1 & - & - & 1.65 & 2.8 & 0.55 \\
Coal bed & 1 & 4 & 20 & - & - & 6 \\
Coal roof & 1 & - & - & 6.9 & - & 1.6 \\
\hline
\end{tabular}

"In coal and rock failure processes, a variety of energies such as elastic energy, expansion energy of compressed gas, thermal energy, sound energy, and electromagnetic energy will be dissipated" [10]. By monitoring the system to receive these energy signals and analyze their characteristics, it is possible to methodically characterize, and therefore predict, natural disasters [11-16]. A simulation experiment of coal failure under forced vibration conditions was conducted in this paper. The acceleration response and microvibration signals during the experiment were collected and analyzed. To investigate the characteristics of these signals under forced 
TABLE 3: Technical data of the acceleration sensor.

\begin{tabular}{lclc}
\hline & Main technical parameters & & \\
\hline Model & YD-32T & Linear & $\leq 1 \%$ \\
Sensitivity $\mathrm{V} / \mathrm{ms}^{2}$ & 0.1 & Transverse sensitivity & $\leq 5 \%$ \\
Frequency range $(\mathrm{Hz})(+10 \%)$ & $10 \sim 6000$ & Output amplitude & $\pm 5 \mathrm{VP}$ \\
Install resonance point $(\mathrm{Hz})$ & $23 \mathrm{~K}$ & Output offset voltage & Supply current \\
Range $\mathrm{m} / \mathrm{s}^{2}(+10 \%)$ & 20 & Excitation voltage & $2 \sim 20 \mathrm{~mA}$ \\
Resolution $\left(\mathrm{m} / \mathrm{s}^{2}\right)$ & 0.0002 & Output impedance & $9 \mathrm{~V}$ \\
Weight $(\mathrm{g})$ & 40 & Shell insulation resistance & $\leq 150 \Omega$ \\
Geometry $(\mathrm{mm})$ & Six party $18 \times 18 \times 23$ & Discharge time constant & $>108 \Omega$ \\
Output mode & Top output & Year stability & \\
Mounting screw & $\mathrm{M} 5$ & & $3 \%$ \\
Operating temperature range & $-40^{\circ} \mathrm{C} \sim+80^{\circ} \mathrm{C}$ & $\mathrm{s}$ \\
\hline
\end{tabular}

TABLE 4: Technical data of microseism sensor.

\begin{tabular}{lcc}
\hline Index/model & Unit & SF1500S/SF1500SN \\
\hline $\begin{array}{l}\text { Linear output range } \\
\text { Sensitivity }\end{array}$ & g peak value & \pm 3 \\
$\begin{array}{l}\text { (differential) } \\
\text { Frequency response }\end{array}$ & $\mathrm{V} / \mathrm{g}$ & $1.2(2.4)$ \\
$\begin{array}{l}\text { Frequency response } \\
\text { (differential signal) }\end{array}$ & $\mathrm{Hz}$ & $\mathrm{DC}$ to 1500 \\
$\begin{array}{l}\text { Dynamic range } \\
\text { (100 Hz BW) }\end{array}$ & $\mathrm{DC}$ to 5000 \\
$\begin{array}{l}\text { Noise }(10 \text { to } 1000 \mathrm{~Hz}) \\
\text { Transverse impedance }\end{array}$ & $\mathrm{ngrms} / \sqrt{\mathrm{Hz}}$ & 120 \\
$\begin{array}{l}\text { Impact of restrictions } \\
\text { Vibration }\end{array}$ & $\mathrm{g}$ peak value & 300 to 500 \\
$\begin{array}{l}\text { (20 Hz-2000 Hz) } \\
\text { Operating } \\
\text { temperature }\end{array}$ & $\mathrm{g}$ peak value & $>40$ \\
$\begin{array}{l}\text { Temperature } \\
\text { sensitivity coefficient }\end{array}$ & ${ }^{\circ} \mathrm{C}$ & 1500 \\
$\begin{array}{l}\text { Drift thermal } \\
\text { coefficient }\end{array}$ & $\mathrm{ppm} /{ }^{\circ} \mathrm{C}$ & 60 \\
$\begin{array}{l}\text { Linearity error } \\
\text { Input voltage }\end{array}$ & $\mu \mathrm{gg} /{ }^{\circ} \mathrm{C}$ & 40 to +125 \\
Static current & $\%$ full scale & 75 \\
\hline
\end{tabular}

vibration conditions as compared to site conditions is a beneficial resource for the formation of an effective method to predict and prevent outbursts.

\section{Experimental Method}

2.1. Basic Approach. While a variety of vibration forms exist in an underground coalface, a specific form of vibration was selected to conduct this experiment. Figure 1 shows the sketch map of forced vibration specimen. This design imitates the deformation and force of a multiple-degree-of-freedom forced vibration system, detailed in Figure 2. It can reflect the influence of vibration caused by seismic activity to natural

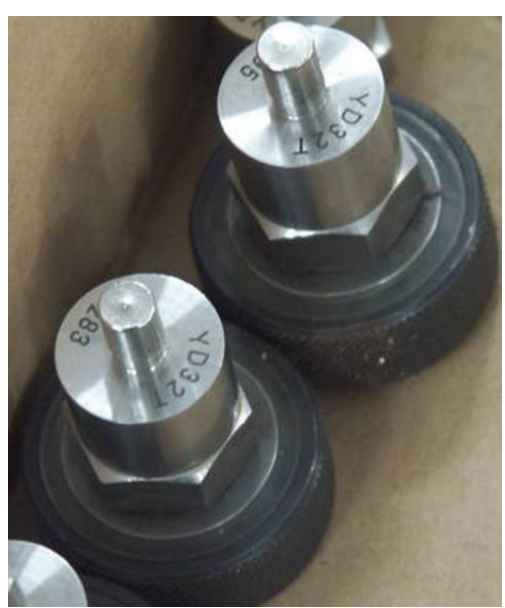

Figure 6: Acceleration transducer.

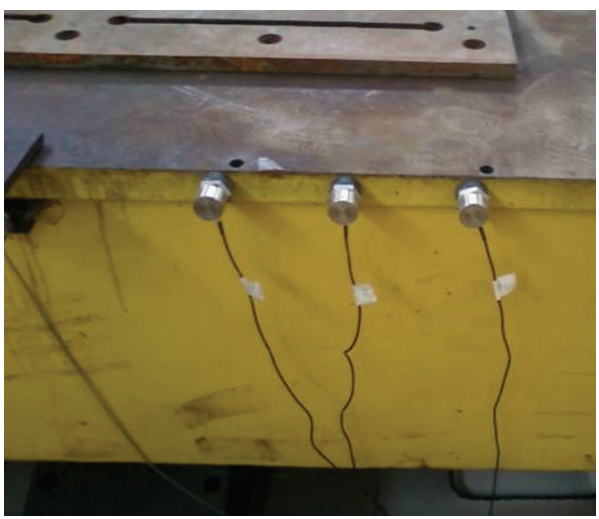

FIGURE 7: Calibration of acceleration transducer.

strata and coal beds. Other forms of vibrational influence will be explored in future research.

Different strata were simulated by a 10-layer steel frame located at different heights on a vibration table. The vibration table provided exciting force (with differing maximum acceleration peak and frequency sine wave load) in the horizontal 
TABLE 5: Setting of experimental parameters.

\begin{tabular}{|c|c|c|c|c|c|c|c|c|c|}
\hline $\begin{array}{l}\text { Working } \\
\text { condition }\end{array}$ & $\begin{array}{l}\text { Frequency } \\
\quad(\mathrm{hz})\end{array}$ & $\begin{array}{c}\text { Input } \\
\text { acceleration }\end{array}$ & $\begin{array}{c}\text { Vibration } \\
\text { duration } \\
\text { (s) }\end{array}$ & $\begin{array}{l}\text { Vibration } \\
\text { cycles }\end{array}$ & $\begin{array}{l}\text { Working } \\
\text { condition }\end{array}$ & $\begin{array}{l}\text { Frequency } \\
\quad(\mathrm{hz})\end{array}$ & $\begin{array}{c}\text { Input } \\
\text { acceleration }\end{array}$ & $\begin{array}{c}\text { Vibration } \\
\text { duration (s) }\end{array}$ & $\begin{array}{c}\text { Vibration } \\
\text { cycles }\end{array}$ \\
\hline 1 & White noise & $0.02 \mathrm{~g}$ & 15.0 & - & 43 & 30 & $0.5 \mathrm{~g}$ & 8.0 & 240 \\
\hline 2 & 1 & $0.02 \mathrm{~g}$ & 30.0 & 30 & 44 & White noise & $0.02 \mathrm{~g}$ & 15.0 & - \\
\hline 3 & 5 & $0.02 \mathrm{~g}$ & 6.0 & 30 & 45 & 32 & $0.5 \mathrm{~g}$ & 7.5 & 240 \\
\hline 4 & 10 & $0.02 \mathrm{~g}$ & 6.0 & 60 & 46 & White noise & $0.02 \mathrm{~g}$ & 15.0 & - \\
\hline 5 & 15 & $0.02 \mathrm{~g}$ & 4.0 & 60 & 47 & 34 & $0.5 \mathrm{~g}$ & 7.1 & 240 \\
\hline 6 & 20 & $0.02 \mathrm{~g}$ & 3.0 & 60 & 48 & White noise & $0.02 \mathrm{~g}$ & 15.0 & - \\
\hline 7 & 24 & $0.02 \mathrm{~g}$ & 5.0 & 120 & 49 & 24 & $0.75 \mathrm{~g}$ & 10.0 & 240 \\
\hline 8 & White noise & $0.02 \mathrm{~g}$ & 15.0 & - & 50 & White noise & $0.02 \mathrm{~g}$ & 15.0 & - \\
\hline 9 & 1 & $0.1 \mathrm{~g}$ & 30.0 & 30 & 51 & 27 & $0.75 \mathrm{~g}$ & 8.9 & 240 \\
\hline 10 & White noise & $0.02 \mathrm{~g}$ & 15.0 & - & 52 & White noise & $0.02 \mathrm{~g}$ & 15.0 & - \\
\hline 11 & 5 & $0.1 \mathrm{~g}$ & 6.0 & 30 & 53 & 30 & $0.75 \mathrm{~g}$ & 8.0 & 240 \\
\hline 12 & White noise & $0.02 \mathrm{~g}$ & 15.0 & - & 54 & White noise & $0.02 \mathrm{~g}$ & 15.0 & - \\
\hline 13 & 10 & $0.1 \mathrm{~g}$ & 12.0 & 120 & 55 & 32 & $0.75 \mathrm{~g}$ & 7.5 & 240 \\
\hline 14 & White noise & $0.02 \mathrm{~g}$ & 15.0 & - & 56 & White noise & $0.02 \mathrm{~g}$ & 15.0 & - \\
\hline 15 & 15 & $0.1 \mathrm{~g}$ & 8.0 & 120 & 57 & 34 & $0.75 \mathrm{~g}$ & 7.1 & 240 \\
\hline 16 & White noise & $0.02 \mathrm{~g}$ & 15.0 & - & 58 & White noise & $0.02 \mathrm{~g}$ & 15.0 & - \\
\hline 17 & 20 & $0.1 \mathrm{~g}$ & 6.0 & 120 & 59 & 28 & $1.5 \mathrm{~g}$ & 8.6 & 240 \\
\hline 18 & White noise & $0.02 \mathrm{~g}$ & 15.0 & - & 60 & White noise & $0.02 \mathrm{~g}$ & 15.0 & - \\
\hline 19 & 24 & $0.1 \mathrm{~g}$ & 5.0 & 120 & 61 & 29 & $1.5 \mathrm{~g}$ & 8.3 & 240 \\
\hline 20 & White noise & $0.02 \mathrm{~g}$ & 15.0 & - & 62 & White noise & $0.02 \mathrm{~g}$ & 15.0 & - \\
\hline 21 & 27 & $0.1 \mathrm{~g}$ & 4.4 & 120 & 63 & 30 & $1.5 \mathrm{~g}$ & 8.0 & 240 \\
\hline 22 & White noise & $0.02 \mathrm{~g}$ & 15.0 & - & 64 & White noise & $0.02 \mathrm{~g}$ & 15.0 & - \\
\hline 23 & 30 & $0.1 \mathrm{~g}$ & 4.0 & 120 & 65 & 31 & $1.5 \mathrm{~g}$ & 7.7 & 240 \\
\hline 24 & White noise & $0.02 \mathrm{~g}$ & 15.0 & - & 66 & White noise & $0.02 \mathrm{~g}$ & 15.0 & - \\
\hline 25 & 32 & $0.1 \mathrm{~g}$ & 3.8 & 120 & 67 & 32 & $1.5 \mathrm{~g}$ & 7.5 & 240 \\
\hline 26 & White noise & $0.02 \mathrm{~g}$ & 15.0 & - & 68 & White noise & $0.02 \mathrm{~g}$ & 15.0 & - \\
\hline 27 & 34 & $0.1 \mathrm{~g}$ & 3.5 & 120 & 69 & 33 & $1.5 \mathrm{~g}$ & 7.3 & 240 \\
\hline 28 & White noise & $0.02 \mathrm{~g}$ & 15.0 & - & 70 & White noise & $0.02 \mathrm{~g}$ & 15.0 & - \\
\hline 29 & 2 & $0.5 \mathrm{~g}$ & 15.0 & 30 & 71 & 34 & $1.5 \mathrm{~g}$ & 7.1 & 240 \\
\hline 30 & White noise & $0.02 \mathrm{~g}$ & 15.0 & - & 72 & White noise & $0.02 \mathrm{~g}$ & 15.0 & - \\
\hline 31 & 5 & $0.5 \mathrm{~g}$ & 6.0 & 30 & 73 & 36 & $1.5 \mathrm{~g}$ & 6.7 & 240 \\
\hline 32 & White noise & $0.02 \mathrm{~g}$ & 15.0 & - & 74 & White noise & $0.02 \mathrm{~g}$ & 15.0 & - \\
\hline 33 & 10 & $0.5 \mathrm{~g}$ & 12.0 & 120 & 75 & 35 & $1.5 \mathrm{~g}$ & 57.1 & 2000 \\
\hline 34 & White noise & $0.02 \mathrm{~g}$ & 15.0 & - & 76 & White noise & $0.02 \mathrm{~g}$ & 15.0 & - \\
\hline 35 & 15 & $0.5 \mathrm{~g}$ & 8.0 & 120 & 77 & 20 & $1.5 \mathrm{~g}$ & 24.0 & 480 \\
\hline 36 & White noise & $0.02 \mathrm{~g}$ & 15.0 & - & 78 & White noise & $0.02 \mathrm{~g}$ & 15.0 & - \\
\hline 37 & 20 & $0.5 \mathrm{~g}$ & 6.0 & 120 & 79 & 15 & $1.2 \mathrm{~g}$ & 16.0 & 240 \\
\hline 38 & White noise & $0.02 \mathrm{~g}$ & 15.0 & - & 80 & White noise & $0.02 \mathrm{~g}$ & 15.0 & - \\
\hline 39 & 24 & $0.5 \mathrm{~g}$ & 10.0 & 240 & 81 & 10 & $1.5 \mathrm{~g}$ & 24.0 & 240 \\
\hline 40 & White noise & $0.02 \mathrm{~g}$ & 15.0 & - & 82 & White noise & $0.02 \mathrm{~g}$ & 15.0 & - \\
\hline 41 & 27 & $0.5 \mathrm{~g}$ & 8.9 & 240 & 83 & 5 & $2.4 \mathrm{~g}$ & 24.0 & 120 \\
\hline 42 & White noise & $0.02 \mathrm{~g}$ & 15.0 & - & & & & & \\
\hline
\end{tabular}


TABLE 6: Natural vibration frequency of the specimen.

\begin{tabular}{|c|c|c|c|c|c|c|c|}
\hline $\begin{array}{l}\text { Work } \\
\text { condition }\end{array}$ & $\begin{array}{c}\text { Natural } \\
\text { frequency (hz) }\end{array}$ & $\begin{array}{c}\text { Work } \\
\text { condition }\end{array}$ & $\begin{array}{c}\text { Natural } \\
\text { frequency }(\mathrm{hz})\end{array}$ & $\begin{array}{c}\text { Work } \\
\text { condition }\end{array}$ & $\begin{array}{c}\text { Natural } \\
\text { frequency }(h z)\end{array}$ & $\begin{array}{c}\text { Work } \\
\text { condition }\end{array}$ & $\begin{array}{c}\text { Natural } \\
\text { frequency (hz) }\end{array}$ \\
\hline 1 & 49.76 & 26 & 42.48 & 46 & 42.39 & 66 & 37.67 \\
\hline 8 & 49.72 & 28 & 42.48 & 48 & 42.37 & 68 & 39.16 \\
\hline 10 & 49.73 & 30 & 42.39 & 50 & 42.49 & 70 & 39.19 \\
\hline 12 & 49.71 & 32 & 42.38 & 52 & 42.37 & 72 & 39.19 \\
\hline 14 & 49.76 & 34 & 42.48 & 54 & 42.37 & 74 & 39.18 \\
\hline 16 & 44.50 & 36 & 42.35 & 56 & 42.37 & 76 & 39.20 \\
\hline 18 & 44.80 & 38 & 42.47 & 58 & 42.47 & 78 & 26.85 \\
\hline 20 & 44.80 & 40 & 42.46 & 60 & 39.17 & 80 & 28.80 \\
\hline 22 & 44.50 & 42 & 42.49 & 62 & 37.68 & 82 & 28.95 \\
\hline 24 & 42.48 & 44 & 42.37 & 64 & 39.18 & & \\
\hline
\end{tabular}

TABLE 7: Extreme and enhanced coefficient of acceleration response $(0.02 \mathrm{~g})$.

\begin{tabular}{lccccccc}
\hline Shock excitation frequency $(\mathrm{Hz})$ & $a 0(\mathrm{~g})$ & $a 1(\mathrm{~g})$ & $a 2(\mathrm{~g})$ & $a 3(\mathrm{~g})$ & $\mu 1$ & $\mu 2$ & $\mu 3$ \\
\hline 1 & 0.0191 & 0.00272 & 0.00274 & 0.00526 & 1.73 & 1.75 & 3.30 \\
5 & 0.02435 & 0.00472 & 0.00508 & 0.00727 & 1.96 & 2.17 & 3.11 \\
10 & 0.0177 & 0.00340 & 0.00376 & 0.00664 & 1.52 & 1.74 \\
15 & 0.0179 & 0.00338 & 0.00377 & 0.00756 & 1.39 & 1.57 & 3.08 \\
20 & 0.01757 & 0.00407 & 0.00443 & 0.00803 & 1.58 & 1.71 & 3.11 \\
24 & 0.0193 & 0.00403 & 0.00418 & 0.00766 & 1.46 & 1.52 & 2.78 \\
\hline
\end{tabular}

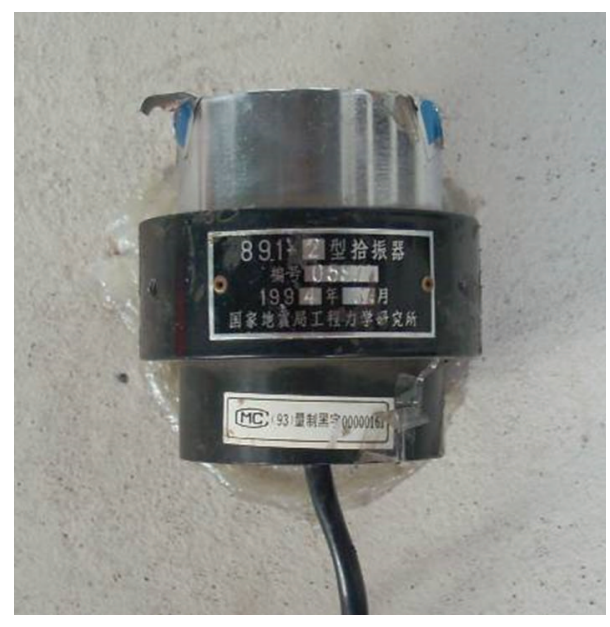

Figure 8: Speed sensor.

direction. The rolling bearing ensures steel frame motion repetition in one direction. Figures 4 and 5 show this design.

\subsection{Experimental Set-Up}

2.2.1. Vibration Table. The one-dimensional horizontal vibration table was provided by Heibei University of Engineering. It is shown in Figure 3. The acquisition system used was a 32-channel data acquisition system. The characters of the vibration table are shown in Table 1.

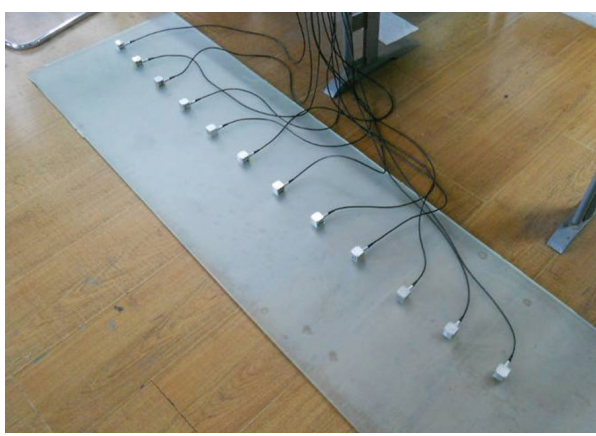

FIGURE 9: Microseism sensor.

2.2.2. Model Box. The model box was a 10-layer independent square steel framework stacking ensemble. Each layer of framework consisted of welded, four-groove steel. The groove steel section size was $60 \mathrm{~mm} \times 30 \mathrm{~mm} \times 3 \mathrm{~mm}$ (length $\times$ width $x$ thickness, referred as $\mathrm{L} \times \mathrm{W} \times \mathrm{H}$ below). The overall internal size of the model box was $400 \mathrm{~mm} \times 400 \mathrm{~mm} \times 650 \mathrm{~mm}(\mathrm{~L} \times$ $\mathrm{W} \times \mathrm{H}$ ). Four rolling bearings were set up to form free rolling points to reduce friction and deflection between the two square steel frameworks. Clearance between the two layers was $6 \mathrm{~mm}$. Among these 10 layers of independent square steel framework, 3 frameworks were selected for opening 3 square holes $(45 \mathrm{~mm} \times 45 \mathrm{~mm})$ on the frame wall of every framework for installing sensors. In order to effectively lift the specimen after molding, steel bars (diameter $6 \mathrm{~mm}$, spacing $100 \mathrm{~mm}$ ) and hooks were welded on the bottom of the model box. According to this model box design, in-plane 
TABLE 8: Extreme and enhancement coefficient of acceleration response (0.1 g).

\begin{tabular}{lccccccc}
\hline Shock excitation frequency $(\mathrm{Hz})$ & $a 0(\mathrm{~g})$ & $a 1(\mathrm{~g})$ & $a 2(\mathrm{~g})$ & $a 3(\mathrm{~g})$ & $\mu 1$ & $\mu 2$ & $\mu 3$ \\
\hline 1 & 0.0778 & 0.0107 & 0.01 & 0.027 & 1.65 & 1.54 & 4.16 \\
5 & 0.107 & 0.0187 & 0.0193 & 0.04 & 1.77 & 1.88 & 3.89 \\
10 & 0.11 & 0.022 & 0.0267 & 0.0503 & 1.58 & 1.99 & 3.75 \\
15 & 0.13 & 0.0247 & 0.0287 & 0.0513 & 1.40 & 1.65 & 2.95 \\
20 & 0.147 & 0.0247 & 0.0303 & 0.0603 & 1.18 & 1.44 \\
24 & 0.104 & 0.02 & 0.0177 & 0.0403 & 1.35 & 1.19 \\
27 & 0.0953 & 0.019 & 0.0193 & 0.0407 & 1.40 & 1.42 \\
30 & 0.076 & 0.0173 & 0.0187 & 0.038 & 1.59 & 1.72 \\
32 & 0.089 & 0.0197 & 0.0213 & 0.042 & 1.55 & 1.68 \\
34 & 0.0854 & 0.0193 & 0.021 & 0.0423 & 1.58 & 3.50 \\
\hline
\end{tabular}

lateral and torsion deformation is constrained, so only shear deformation along the vibration direction is present.

2.2.3. Specimen. For the purpose of this experiment, the specimen was divided into three parts: the coal roof, coal bed, and coal floor. These three parts consisted of a concrete mixture. Table 2 shows the material and mixing ratios.

$500 \mathrm{~mm}$ of the mixture was poured in the coal roof, $80 \mathrm{~mm}$ in the coal bed, and $70 \mathrm{~mm}$ in the coal floor to simulate stress from overlying strata. The coal floor was cast by concrete and medium sand placement. The coal roof was cast layer-by-layer, where the thickness of each layer was 10 $15 \mathrm{~mm}$. Talc powder was added between every layer to create strata interface. The particle size of coal powder in the coal bed was 0-0.4 mm in diameter. A $100 \mathrm{~mm}$ long roadway (with a net sectional area of $60 \mathrm{~mm} \times 60 \mathrm{~mm}$ ) was established in the coal bed. Before the molding process, four rollers were installed along the direction of vibration between every two steel frames to reduce friction. Because the quality of the steel frame is much lower than the model, the steel frame was retained after molding. In the experiment, therefore, the shear deformation in the frame was limited and the specimen stiffness increased. This caused a vibration frequency greater than the actual, natural value in the measured model.

2.2.4. Sensors. Acceleration, speed and microseism sensor are used in this experiment. Figures 10 and 11 shows these sensors' distribution.

(1) Acceleration Sensor. A YD series voltage output piezoelectric acceleration sensor was used in this experiment which is shown in Figures 6 and 7. It is composed of a piezoelectric accelerometer and special imported ICP chip, which integrates a traditional piezoelectric acceleration sensor and amplifier and uses the same cable for power supply and output signals. Specific parameters of the YD series voltage output piezoelectric acceleration sensor are shown in Table 3.

Three YD-32T acceleration sensors were used in this experiment. These sensors were, respectively, arranged on the 3 different points (the bottom, middle, and top of the specimen) on the specimen's side. 1\#, 2\#, and 3\# acceleration sensors correspond to the bottom of the model specimen, the middle, and the top, respectively. Acceleration sensors are attached to the steel frame by magnet.

(2) Speed Sensor. A speed sensor measured the velocity response and then calculated the natural vibration frequency of the specimen. An 89.1-2 type speed sensor with high sensitivity was provided by Institute of Engineering Mechanics, China Earthquake Administration. The speed sensor which is shown in Figure 8 was fixed to the specimen's top center using Vaseline.

(3) Microseism Sensor. Eight SF1500MEMS capacitive acceleration microseism sensors (which is shown in Figure 9), produced by COLIBRYS Company, were attached to the specimen's surface using modified acrylate adhesive. The main components of the SF1500MEMS microseismic sensor are a silicon element by three-dimensional processing, low power DSP, microcontroller, and temperature sensor. Technical data of this kind microseism sensor is shown in Table 4 .

\subsubsection{Data Acquisition System}

(1) Dynamic Acquisition Instrument. An amplifier and INV306DF signal collecting tester were connected to the acceleration and speed sensors. DASP testing software was employed in the experiment to process signal data. There are 16 channels in the signal collecting tester. AD accuracy was 16 , the maximum sampling frequency was $400 \mathrm{kHz}$, and magnification was 1-16 times.

(2) Coal and Rock Dynamic Disaster Experiment Simulation System of ZDKT-1 (ZDKT-1 System). Microseismic sensors were connected to the ZDKT-1 system [17, 18]. It has 12 microseismic channels. The maximum sampling frequency of this system is $51 \mathrm{kHz}$. In this experiment, the sampling frequency was set to $17067 \mathrm{~Hz}$.

\section{Determination of Specimen Nature Vibration Frequency}

The specimen's natural vibration frequency is affected by material, density, size, and shape factors, reflecting the natural 


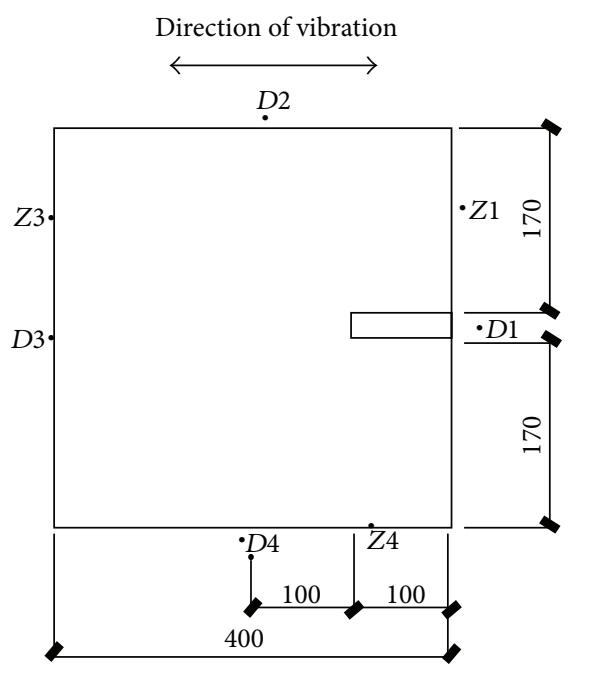

Microseism sensors $(Z)$ and EME sensors $(D)$ layout

(290 $\mathrm{mm}$ vertical dimension from

vibration table)

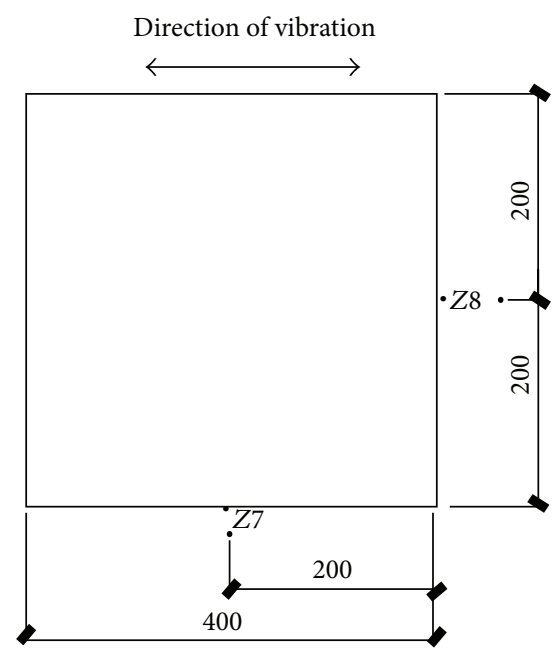

Microseism sensors $(Z)$ and EME

sensors $(D)$ layout

(290 $\mathrm{mm}$ vertical dimension from

vibration table)

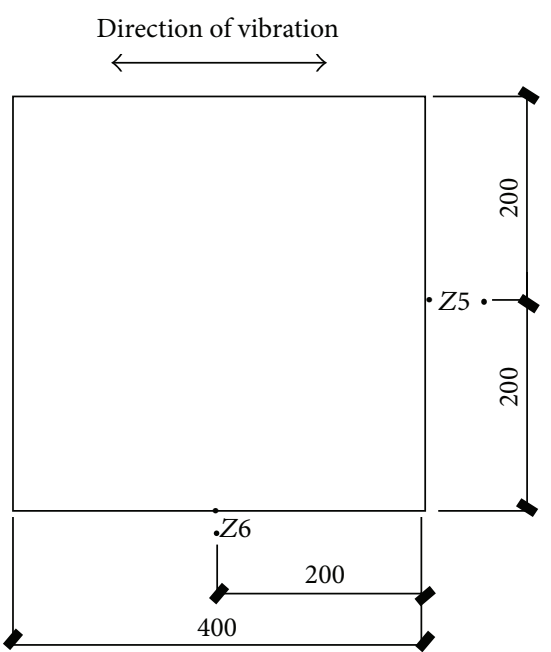

Microseism sensors $(Z)$ and EME

sensors $(D)$ layout

(290 mm vertical dimension from

vibration table)

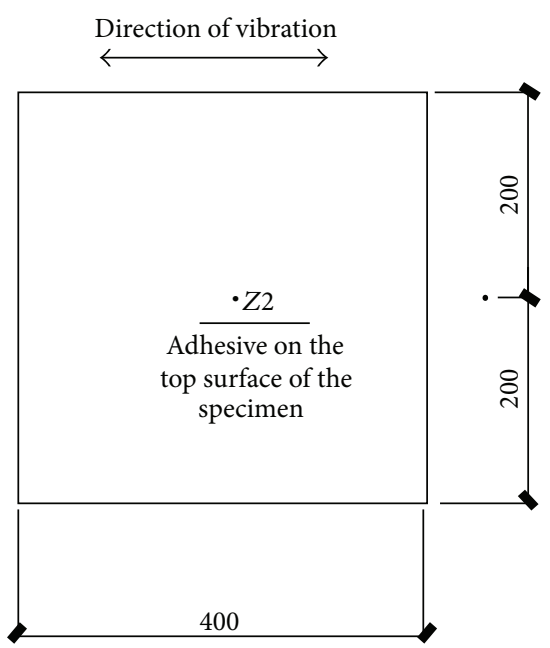

Microseism sensors $(Z)$ and EME

sensors $(D)$ layout

(specimen top surface)

FIGURE 10: Microseism sensor and EME sensors (electromagnetic emission sensors are used for measuring EME signals which are not discussed in this paper) distribution.

dynamic characteristics of specimens. By taping the model specimens to the top, transverse free vibration was produced. The speed sensor fixed on top of the specimen collected vibration signals and then amplified and filtered them. Finally, the spectrum curve was obtained using the vibration signals by fast Fourier transform (FFT). In this experiment, data acquisition frequency was $1300 \mathrm{~Hz}$. The results of the two experiments are as shown in Figure 12. The natural vibration frequency of the specimen was $49.7 \mathrm{~Hz}$.

\section{Experimental Process}

White noise is known as a random signal with a constant power spectral density [19]. In this experiment, a horizontal one-way input shock excitation wave was produced by the synthesis of white noise and a sinusoidal wave (with differing peak acceleration and frequency). The white noise and sinusoidal wave were inputted alternately. White noise scanning acceleration was set to $0.02 \mathrm{~g} ., 0.02 \mathrm{~g}, 0.1 \mathrm{~g}, 0.5 \mathrm{~g}$, 
TABLE 9: Extreme and enhanced coefficient of acceleration response ( $0.5 \mathrm{~g})$.

\begin{tabular}{lccccccc}
\hline Shock excitation frequency $(\mathrm{Hz})$ & $a 0(\mathrm{~g})$ & $a 1(\mathrm{~g})$ & $a 2(\mathrm{~g})$ & $a 3(\mathrm{~g})$ & $\mu 1$ & $\mu 2$ & $\mu 3$ \\
\hline 2 & 0.546 & 0.056 & 0.05533 & 0.0787 & 1.24 & 1.24 & 1.73 \\
5 & 0.5 & 0.0543 & 0.0527 & 0.0717 & 1.10 & 1.10 & 1.49 \\
10 & 0.505 & 0.0697 & 0.057 & 0.1037 & 1.09 & 0.93 \\
15 & 0.5196 & 0.08 & 0.093 & 0.1233 & 1.13 & 1.34 \\
20 & 0.4272 & 0.122 & 0.1747 & 0.2357 & 1.94 & 2.78 \\
24 & 0.511 & 0.0977 & 0.1083 & 0.1393 & 1.34 & 1.48 \\
27 & 0.4959 & 0.107 & 0.0767 & 0.0937 & 1.51 & 1.08 \\
30 & 0.501 & 0.0883 & 0.069 & 0.1007 & 1.23 & 0.96 \\
32 & 0.5088 & 0.089 & 0.0523 & 0.0967 & 1.22 & 0.72 & 1.32 \\
34 & 0.524 & 0.0963 & 0.0477 & 0.092 & 1.29 & 0.64 & 1.33 \\
\hline
\end{tabular}

TABLE 10: Extreme and enhanced coefficient of acceleration response (0.75 g).

\begin{tabular}{lccccccc}
\hline Shock excitation frequency $(\mathrm{Hz})$ & $a 0(\mathrm{~g})$ & $a 1(\mathrm{~g})$ & $a 2(\mathrm{~g})$ & $a 3(\mathrm{~g})$ & $\mu 1$ & $\mu 2$ & $\mu 3$ \\
\hline 24 & 0.7719 & 0.133 & 0.1893 & 0.1687 & 1.21 & 1.72 & 1.53 \\
27 & 0.8053 & 0.169 & 0.1153 & 0.1747 & 1.47 & 1.00 & 1.52 \\
30 & 0.81 & 0.1673 & 0.0767 & 0.145 & 1.45 & 0.66 \\
32 & 0.7636 & 0.1247 & 0.057 & 0.11 & 1.14 & 0.52 & 1.25 \\
34 & 0.7904 & 0.1253 & 0.048 & 0.11 & 1.11 & 0.43 & 0.97 \\
\hline
\end{tabular}

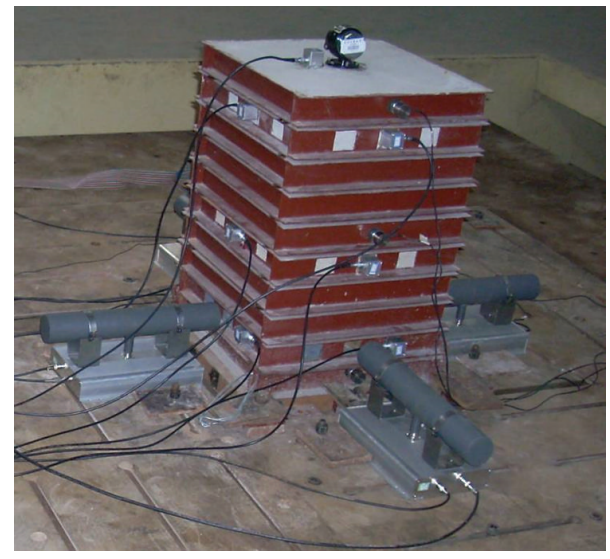

FIGURE 11: Arrangement of each sensor.

$0.75 \mathrm{~g}$, and $1.5 \mathrm{~g}$ peak acceleration, respectively. Experiments were carried out in 5 stages according to the different acceleration peaks. At each stage, the sine wave frequency of the shock excitation wave changed. Table 5 further details the experimental parameters.

These 83 working conditions were performed continuously. The specimen rupture process was such as (1) initial crack opening expansion, (2) derivative crack propagation, (3) crack coalescence, and (4) specimen destruction.

\section{Result and Discussion}

5.1. Specimen Nature Vibration Frequency. The natural vibration frequency of the specimen, which changes during the vibration period, reflects its natural dynamic characteristics.
The random vibration method, which scans white noise, was used in this experiment to measure the specimen's natural vibration frequency. White noise scanning acceleration was set to $0.02 \mathrm{~g}$. The corresponding white noise frequency components were measured to be the same as natural vibration frequency and amplify in tandem. To obtain spectra, we collected signals in the speed sensor and processed these signals by fast Fourier transform (FFT). These spectra reveal the natural vibration frequency in detail.

Here working condition 1 is selected to measured (other working condition have similar process). The white noise signals set in vibration are shown in Figure 13. The result after FFT processing are shown in Figure 14. From this result, it can be known that the specimen's natural vibration frequency was $49.76 \mathrm{~Hz}$, consistent with the result mentioned in Section 3. Table 6 shows the natural vibration frequency of the specimen in all conditions.

The specimen's natural frequency decreases alongside an increase in the amount of vibration. When the coal specimen begins to display obvious failure characteristics, the natural vibration frequency decreases rapidly. It can be seen from Figure 15. As shown in the single-degree-of-freedom forced vibration equation without damping, $f=(1 / 2 \pi) \sqrt{\mathrm{k} / \mathrm{m}}$, natural vibration frequency is mainly related to mass and stiffness. In this experiment, the specimen quality was kept constant. As the amount of vibration increased, cracks began to appear in the coal specimen and gradually intensify. This decreased the specimen's lateral stiffness, reducing the natural vibration frequency.

5.2. Acceleration Response. A total of five acceleration levels, $0.02 \mathrm{~g}, 0.1 \mathrm{~g}, 0.5 \mathrm{~g}, 0.75 \mathrm{~g}$, and $1.5 \mathrm{~g}$, were put into the vibration table, respectively (see Table 5). Four groups of acceleration 

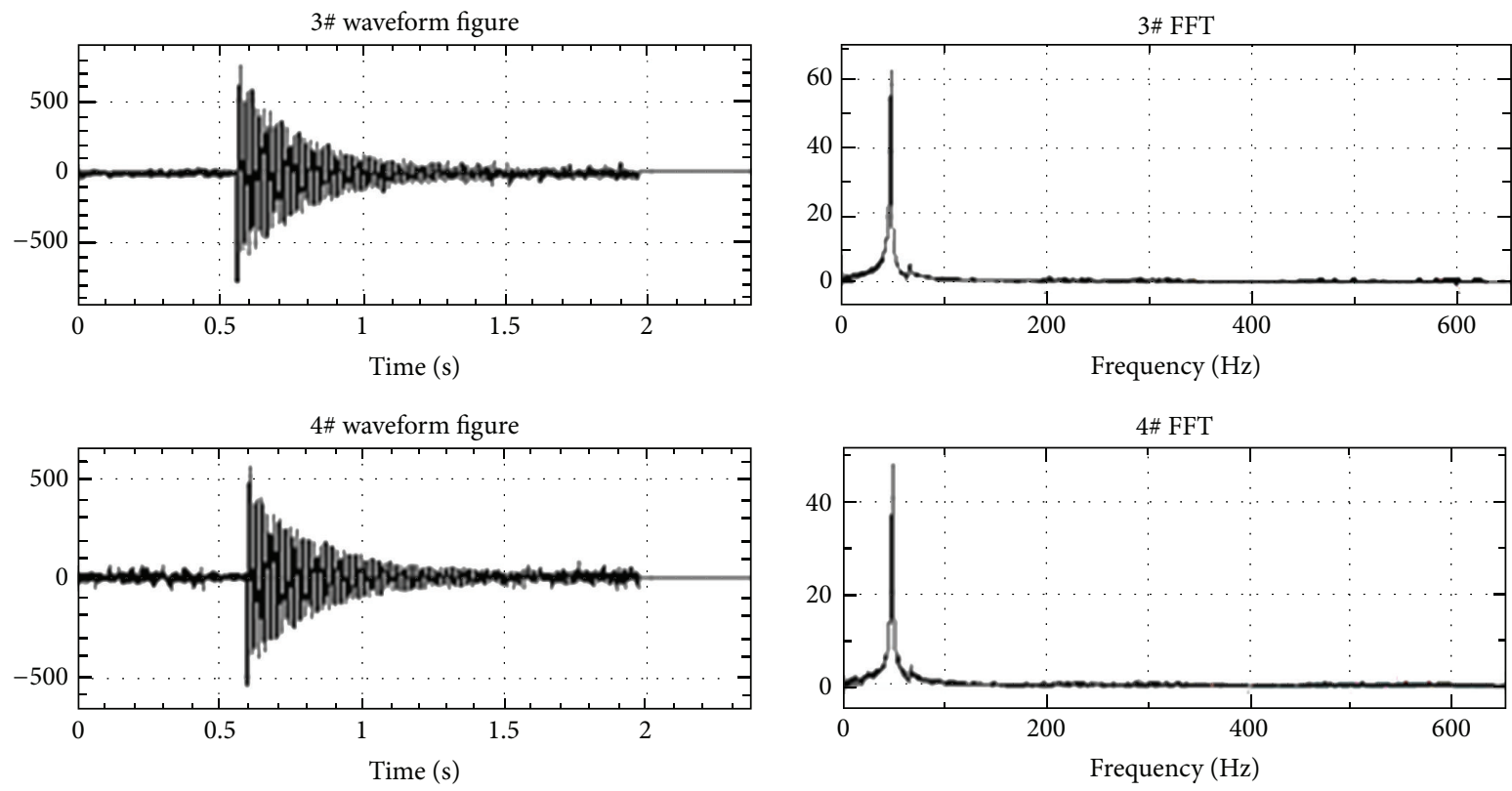

FIGURE 12: Free vibration curve and spectrogram.

TABLE 11: Extreme and enhanced coefficient of acceleration response (1.5 g).

\begin{tabular}{|c|c|c|c|c|c|c|c|}
\hline Shock excitation frequency $(\mathrm{Hz})$ & $a 0(\mathrm{~g})$ & $a 1(\mathrm{~g})$ & $a 2(\mathrm{~g})$ & $a 3(\mathrm{~g})$ & $\mu 1$ & $\mu 2$ & $\mu 3$ \\
\hline 28 & 1.585 & 0.3183 & 0.349 & 1.1753 & 1.41 & 1.54 & 5.19 \\
\hline 29 & 1.5107 & 0.3103 & 0.2153 & 0.8097 & 1.44 & 1.00 & 3.75 \\
\hline 30 & 1.4597 & 0.3043 & 0.1837 & 0.5517 & 1.46 & 0.88 & 2.65 \\
\hline 31 & 1.471 & 0.2703 & 0.1393 & 0.3253 & 1.29 & 0.66 & 1.55 \\
\hline 32 & 1.432 & 0.2513 & 0.1627 & 0.395 & 1.23 & 0.80 & 1.93 \\
\hline 33 & 1.4934 & 0.292 & 0.1523 & 0.4393 & 1.37 & 0.71 & 2.06 \\
\hline 34 & 1.4743 & 0.29 & 0.2407 & 0.623 & 1.38 & 1.14 & 2.96 \\
\hline 36 & 1.5159 & 0.2917 & 0.2283 & 0.5117 & 1.35 & 1.05 & 2.36 \\
\hline 35 & 1.5157 & 0.311 & 0.2237 & 0.5077 & 1.44 & 1.03 & 2.34 \\
\hline 20 & 1.5256 & 0.2873 & 0.3037 & 0.8097 & 1.32 & 1.39 & 3.72 \\
\hline 15 & 1.2108 & 0.2117 & 0.2387 & 0.6663 & 1.22 & 1.38 & 3.85 \\
\hline 10 & 1.6187 & 0.214 & 0.483 & 0.7983 & 0.93 & 2.09 & 3.45 \\
\hline
\end{tabular}

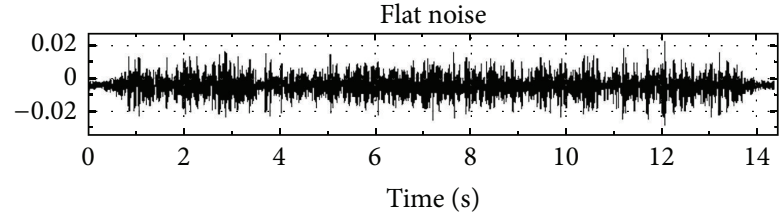

FIGURE 13: White noise signal of vibration table setting.

data were collected for every working condition. Sampling frequency was set to $512 \mathrm{~Hz}$. The 0 \# acceleration sensor indicated the actual acceleration on the vibration table surface. The 1\#-3\# sensors indicated the specimen's bottom, middle, and top acceleration, respectively.

5.2.1. Shock Excitation Frequency Influence on Acceleration Response. Because measured acceleration on the vibration
TABLE 12: Peak value of acceleration response.

\begin{tabular}{lcccc}
\hline Working condition & $a 0(\mathrm{~g})$ & $a 1(\mathrm{~g})$ & $a 2(\mathrm{~g})$ & $a 3(\mathrm{~g})$ \\
\hline 7 & 0.0193 & 0.0677 & 0.056 & 0.1797 \\
19 & 0.104 & 0.14 & 0.1239 & 0.2821 \\
39 & 0.511 & 0.6839 & 0.7581 & 0.9751 \\
49 & 0.7719 & 0.931 & 1.3251 & 1.1809 \\
\hline
\end{tabular}

table was not completely consistent with input acceleration, a different value for altered shock excitation frequency was observed. To acquire shock excitation frequency influence on acceleration response, acceleration response enhancement coefficient $\mu$ is defined. Peak acceleration on the vibration table was set to $a 0$ (0\# sensor measurement), and $a 1, a 2$, and $a 3$ were the peak acceleration from the bottom to top, respectively (1\#-3\# sensor measurements); then, $\mu 1=a 1 / a 0$, 

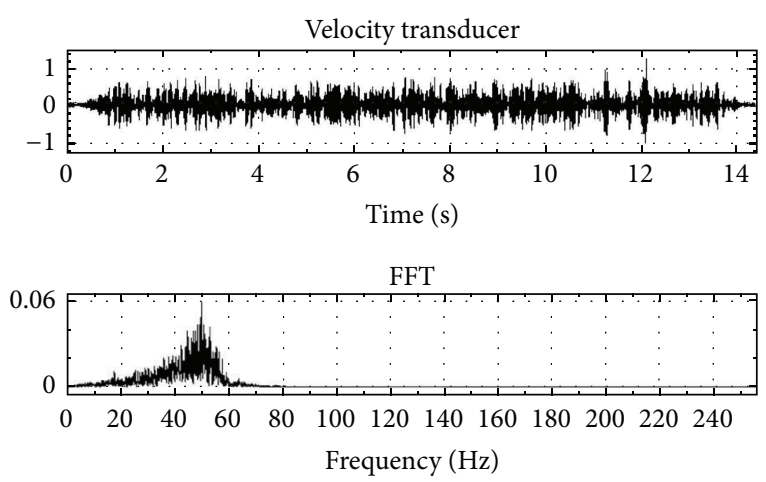

FIGURE 14: Time domain waveform and spectrogram of velocity response signal in working condition 1.

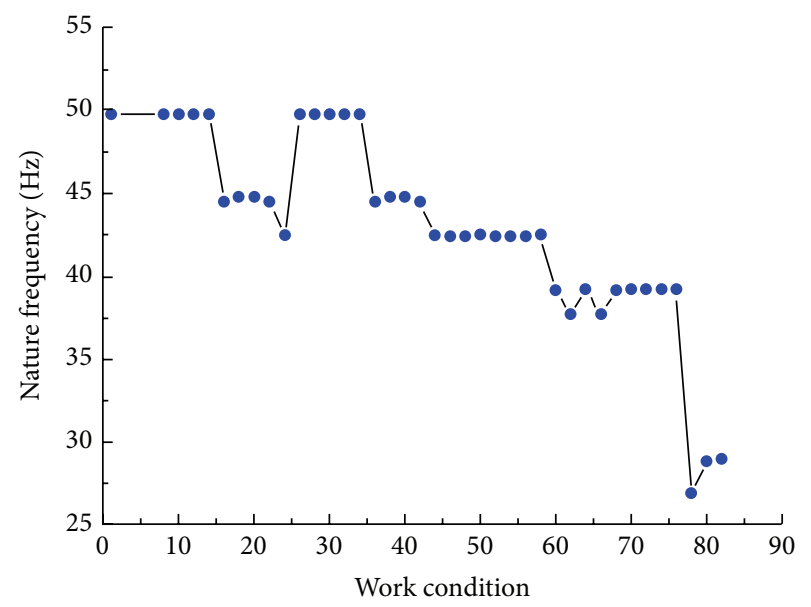

FIGURE 15: Natural vibration frequency change trend curve.

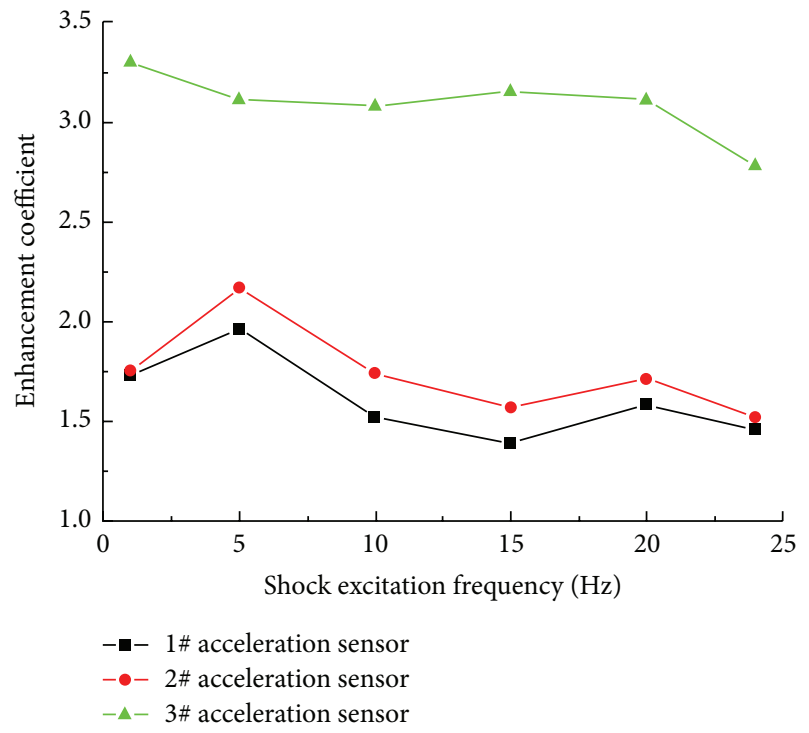

FIGURE 16: Enhancement coefficient curve of the acceleration response $(0.02 \mathrm{~g})$.

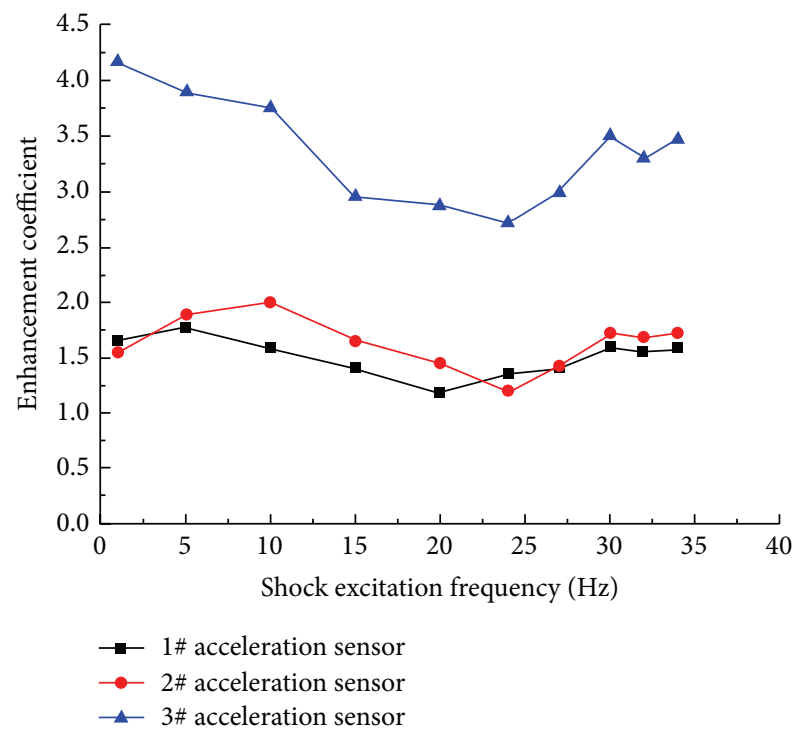

FIGURE 17: Enhancement coefficient curve of the acceleration response $(0.1 \mathrm{~g})$.

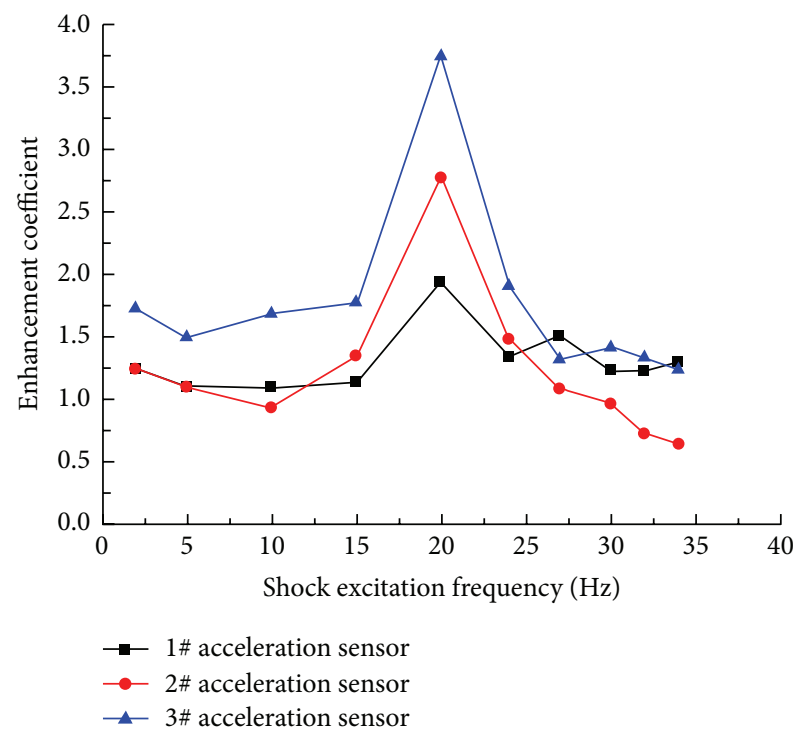

FIGURE 18: Enhancement coefficient curve of the acceleration response $(0.5 \mathrm{~g})$.

$\mu 2=a 2 / a 0$, and $\mu 3=a 3 / a 0$. By comparing different acceleration response enhancement coefficients under a variety of shock excitation frequency conditions, it is possible to obtain the change law at work. Peak acceleration was measured, and acceleration response enhancement coefficient $\mu$ was calculated under different shock excitation frequencies. The results are shown in Tables $7,8,9,10$, and 11 .

(1) Result at Input $0.02 \mathrm{~g}$ Peak Acceleration of Vibration. Figure 16 shows that the enhancement coefficient had no obvious change as shock excitation vibration frequency increased. In this set of experiments, the shock excitation 


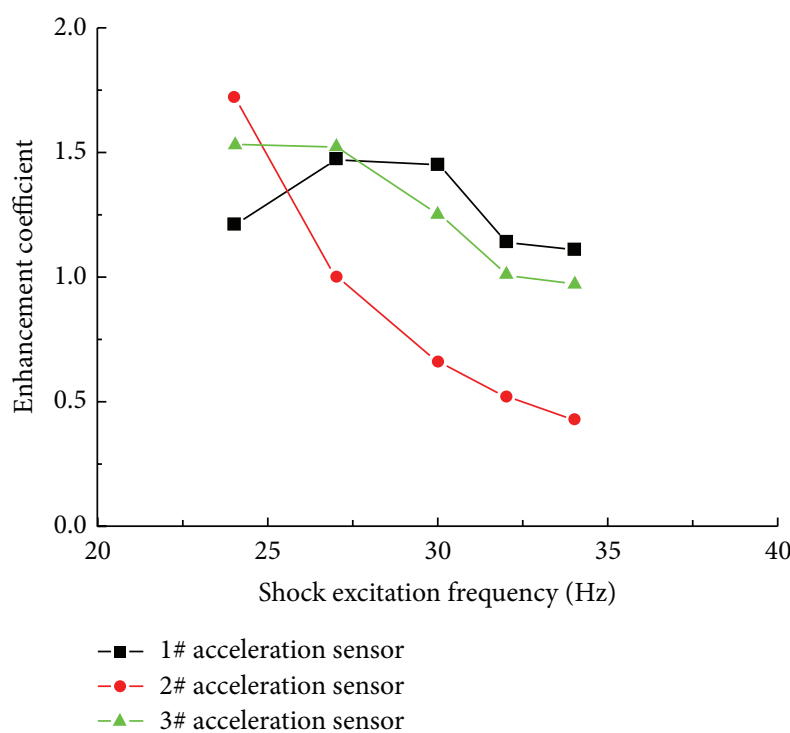

FIGURE 19: Enhancement coefficient curve of the acceleration response $(0.75 \mathrm{~g})$.

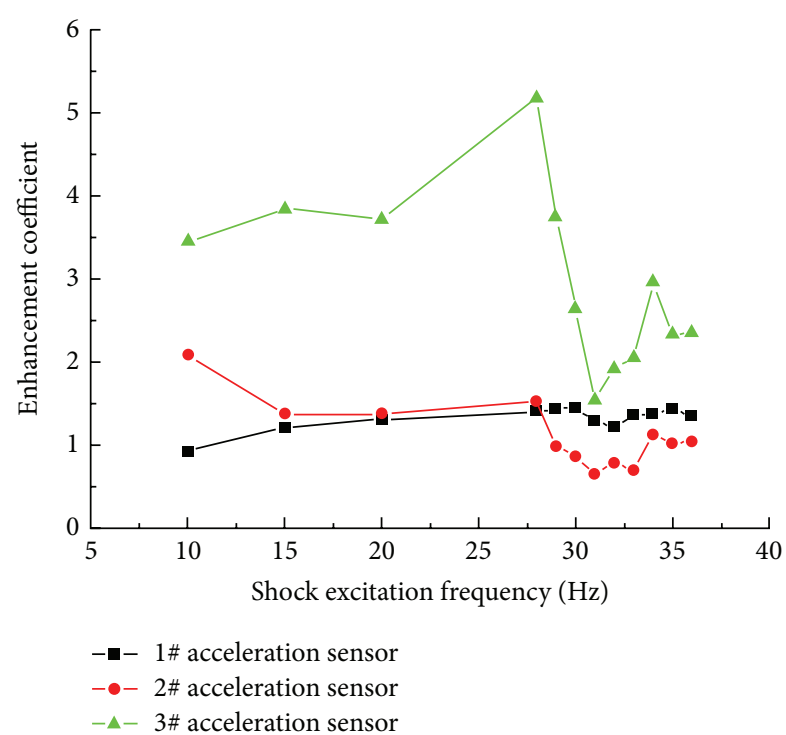

FIGURE 20: Enhancement coefficient curve of the acceleration response $(1.5 \mathrm{~g})$.

frequency was far lower than the natural frequencies of the specimen, preventing resonance phenomenon. Due to the small input acceleration to the vibration table combined with the data collected by microvibration sensor (no effective microvibration signal,) we deduced that the specimen was still in the elastic deformation stage, where no obvious damage occurred. Additionally, the enhancement coefficient increased from bottom to top.

(2) Result at Input $0.1 \mathrm{~g}$ Peak Acceleration of Vibration. As shown in Figure 17, the enhancement coefficient declined
TABLE 13: IMF component percentage of energy of original microseism signals by EEMD in working condition 29.

\begin{tabular}{lc}
\hline IMF component & Energy percentage (\%) \\
\hline IMF_h1 & 51.1 \\
IMF_h2 & 19.3 \\
IMF_h3 & 12.4 \\
IMF_h4 & 12.4 \\
IMF_h5 & 3 \\
IMF_h6 & 0.795 \\
IMF_h7 & 0.324 \\
IMF_h8 & 0.639 \\
IMF_h9 & 0.273 \\
IMF_h10 & 11.6 \\
IMF_h11 & 0.0243 \\
IMF_h12 & 0.02 \\
IMF_h13 & 0.0191 \\
IMF_h14 & 0.00991 \\
IMF_h15 & 0.00378 \\
IMF_h16 & $4.71 E-05$ \\
IMF_h17 & $1.03 E-05$ \\
\hline
\end{tabular}

TABLE 14: IMF component energy percentages of effective microseism signals by EEMD in working condition 29.

\begin{tabular}{lc}
\hline IMF component & Energy percentage (\%) \\
\hline IMF_h1 & 66.8 \\
IMF_h2 & 15.6 \\
IMF_h3 & 14.2 \\
IMF_h4 & 2.88 \\
IMF_h5 & 0.222 \\
IMF_h6 & 0.115 \\
IMF_h7 & 0.0434 \\
IMF_h8 & 0.0249 \\
IMF_h9 & 0.0356 \\
IMF_h10 & 0.0218 \\
IMF_h11 & 0.0113 \\
IMF_h12 & 0.00279 \\
IMF_h13 & 0.000226 \\
IMF_h14 & 0.000126 \\
IMF_h15 & 0.00023 \\
IMF_h16 & 0.000115 \\
IMF_h17 & 0.000104
\end{tabular}

when shock excitation frequency was less than $24 \mathrm{~Hz}$ and then rose when shock excitation frequency was greater than $24 \mathrm{~Hz}$ under $0.1 \mathrm{~g}$ acceleration input to the vibration table. In these stages, microfractures and a web of micropores began to appear, increasing the damping ratio and causing the enhancement coefficient to decline. When shock excitation frequency was greater than $24 \mathrm{~Hz}$, it grew near to the specimen's natural vibration frequency $(44.5 \mathrm{~Hz})$. Though the 

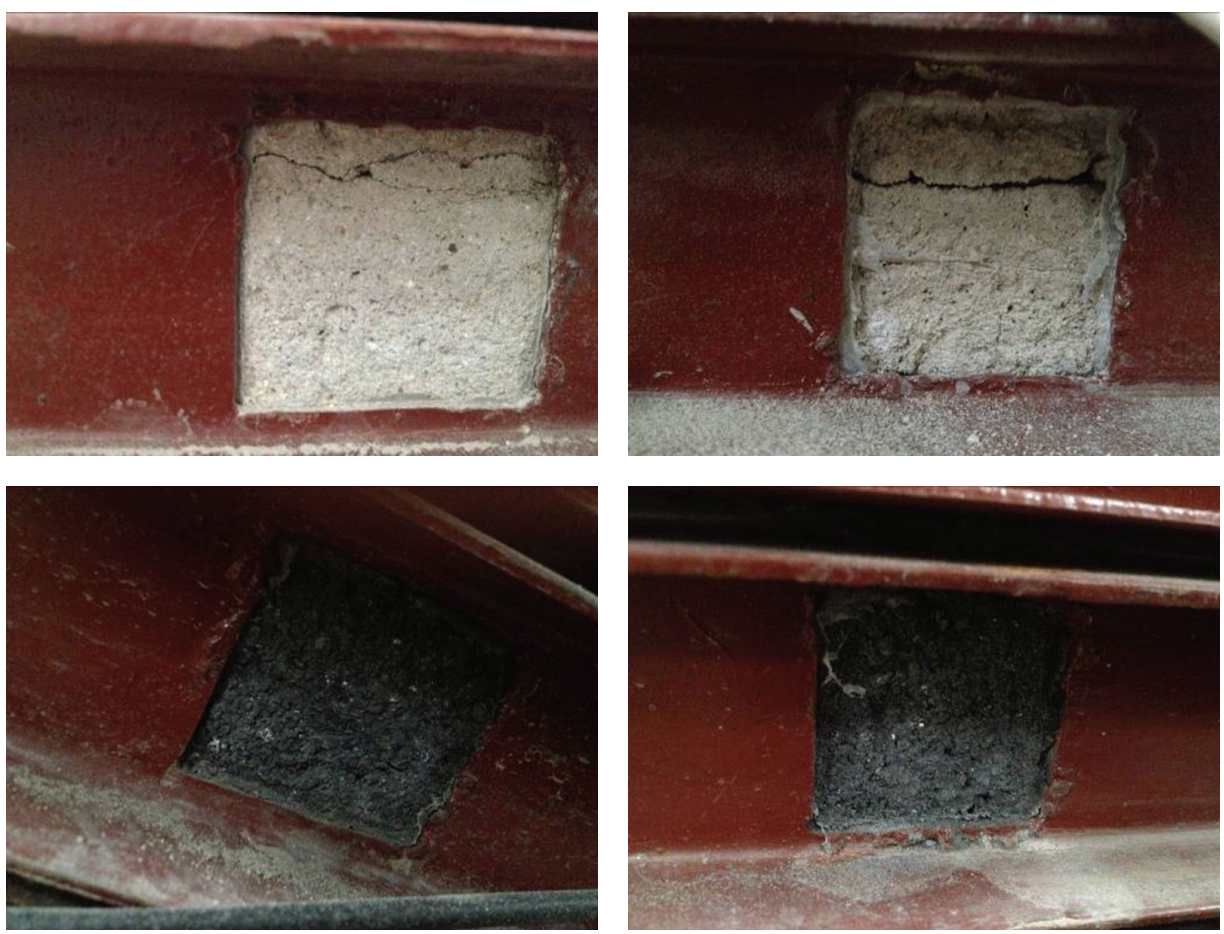

FIGURE 21: Destruction of the specimen side figure.

TABLE 15: IMF component energy percentage for selected effective microseism signals by EEMD.

\begin{tabular}{|c|c|c|c|c|c|}
\hline IMF components & $\begin{array}{c}\text { Working condition } \\
29 \\
(\%) \\
\end{array}$ & $\begin{array}{c}\text { Working condition } \\
35 \\
(\%) \\
\end{array}$ & $\begin{array}{c}\text { Working condition } \\
37 \\
(\%) \\
\end{array}$ & $\begin{array}{c}\text { Working condition } \\
41 \\
(\%) \\
\end{array}$ & $\begin{array}{c}\text { Working condition } \\
47 \\
(\%) \\
\end{array}$ \\
\hline IMF_h1 & 66.8 & 80.3 & 10 & 85.4 & 55.9 \\
\hline IMF_h2 & 15.6 & 10.4 & 11.3 & 13.6 & 42.4 \\
\hline IMF_h3 & 14.2 & 5.74 & 61.2 & 0.49 & 1.23 \\
\hline IMF_h4 & 2.88 & 3.05 & 16.3 & 0.311 & 0.293 \\
\hline IMF_h5 & 0.222 & 0.374 & 0.959 & 0.0857 & 0.0826 \\
\hline IMF_h6 & 0.115 & 0.0826 & 0.146 & 0.0317 & 0.0314 \\
\hline IMF_h7 & 0.0434 & 0.0449 & 0.0343 & 0.016 & 0.0161 \\
\hline IMF_h8 & 0.0249 & 0.0198 & 0.0222 & 0.0088 & 0.00861 \\
\hline IMF_h9 & 0.0356 & 0.00868 & 0.00808 & 0.00421 & 0.0042 \\
\hline IMF_h10 & 0.0218 & 0.00266 & 0.00393 & 0.00286 & 0.00213 \\
\hline IMF_h11 & 0.0113 & 0.000972 & 0.00388 & 0.00128 & 0.0012 \\
\hline IMF_h12 & 0.00279 & 0.000577 & 0.00114 & 0.000586 & 0.000455 \\
\hline IMF_h13 & 0.000226 & 0.000359 & 0.00086 & 0.000305 & 0.000322 \\
\hline IMF_h14 & 0.000126 & 0.000242 & 0.00114 & 0.000217 & 0.000105 \\
\hline IMF_h15 & 0.00023 & 0.000248 & $1.78 E-05$ & $4.52 E-05$ & 0.000184 \\
\hline IMF_hl6 & 0.000115 & $3.72 E-05$ & - & $3.82 E-05$ & - \\
\hline IMF_h17 & 0.000104 & - & - & - & - \\
\hline
\end{tabular}

resonance phenomenon was not observed, the acceleration response peak did enlarge according to resonance theory. Because a $0.1 \mathrm{~g}$ acceleration peak is still not very high and microsensors do not collect any obvious rupture signals from the specimen, this paper assumes the specimen to have remained in an apparent linear elastic deformation stage.
The results also indicate that the enhancement coefficient increased from bottom to top.

(3) Result at Input $0.5 \mathrm{~g}$ Peak Acceleration of Vibration. As shown in Figure 18, the enhancement coefficient inclined when shock excitation frequency is less than $20 \mathrm{~Hz}$ and 


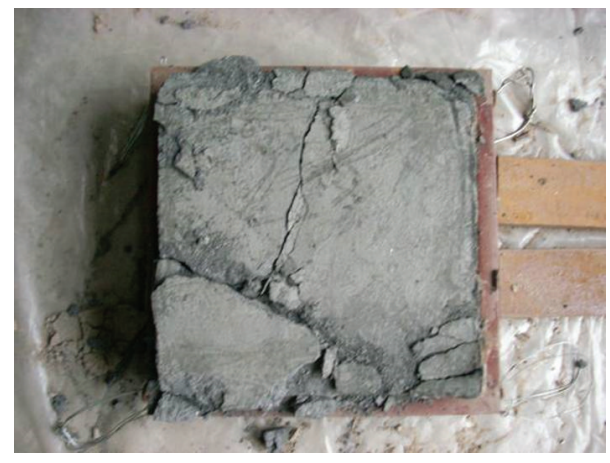

FIGURE 22: Coal burst figure.

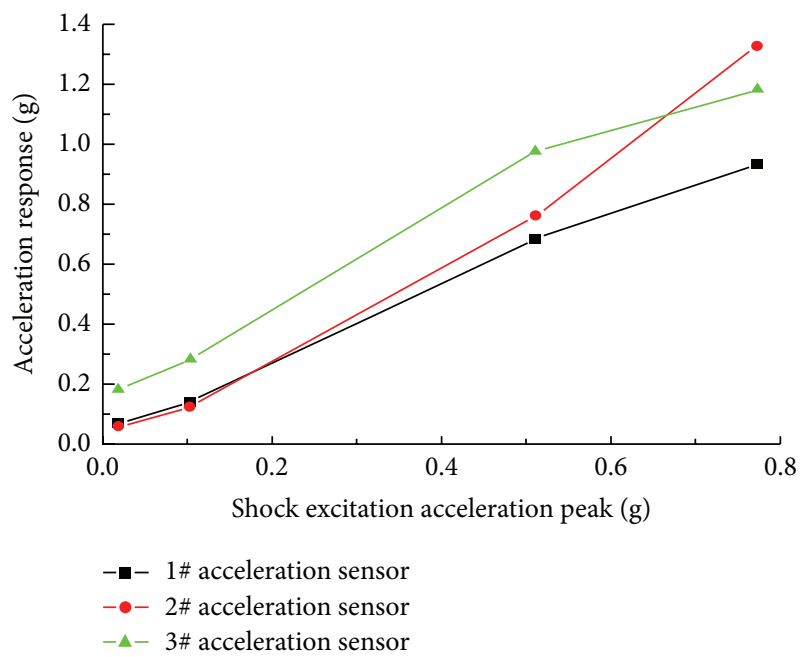

FIGURE 23: Relationship curve of acceleration response and shock excitation acceleration peak value.

declined when shock excitation frequency was greater than $20 \mathrm{~Hz}$ under $0.5 \mathrm{~g}$ acceleration input to the vibration table. The acceleration response amplitude at $20 \mathrm{~Hz}$ was greater than any other frequency. A resonance phenomenon was observed to occur in the specimen (where the specimen natural vibration frequency was $20 \mathrm{~Hz}$ in our experiment). This differs from the result in Section 5.1, $42.5 \mathrm{~Hz}$, which was concluded as the specimen's natural vibration. The difference can be attributed to the $0.5 \mathrm{~g}$ acceleration input to the vibration table in this section of the experiment, 249 times greater than the $0.002 \mathrm{~g}$ used to measure natural vibration frequency by white noise scanning in Section 5.1. When the acceleration peak reached $0.5 \mathrm{~g}$, damage occurred within the specimen. Crack propagation, damping ratio increases, and lateral stiffness decreases altogether caused the specimen's natural vibration frequency to drop to $20 \mathrm{~Hz}$. Damage to the specimen can be demonstrated by microseism signals. In addition, $a 3$ was larger than $a 1$ or $a 2$ when shock excitation was smaller than $24 \mathrm{~Hz}$. When shock excitation exceeded $24 \mathrm{~Hz}, a 2$ shrank significantly. This phenomenon differs from observations gathered at 0.02 or $0.1 \mathrm{~g}$ acceleration inputs to
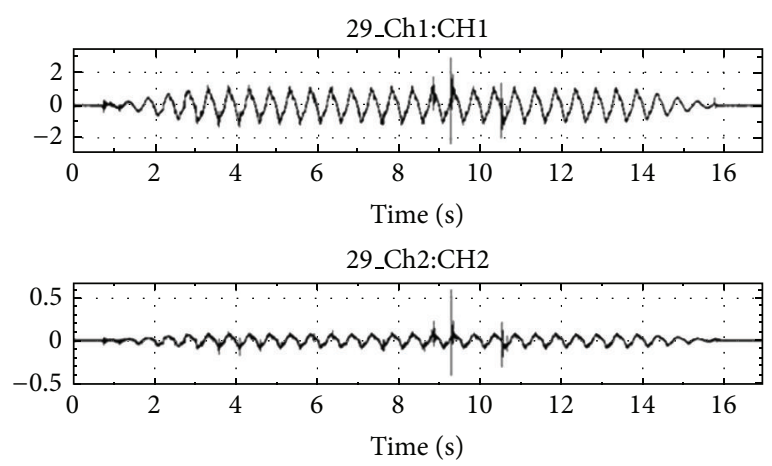

29_Ch3:CH3
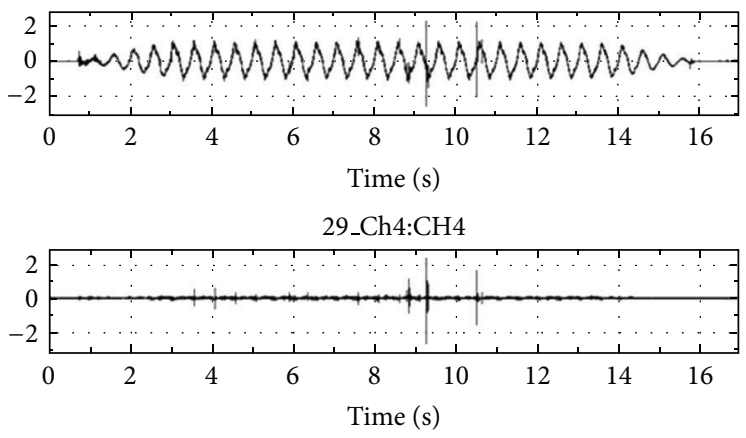

29_Ch6:CH6

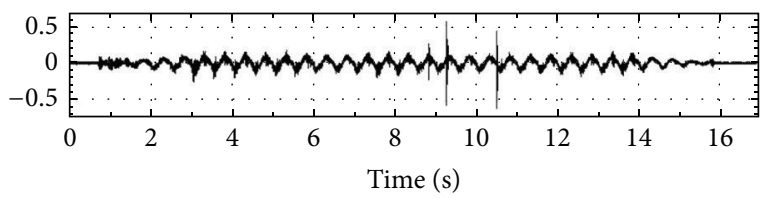

29_Ch7:CH7

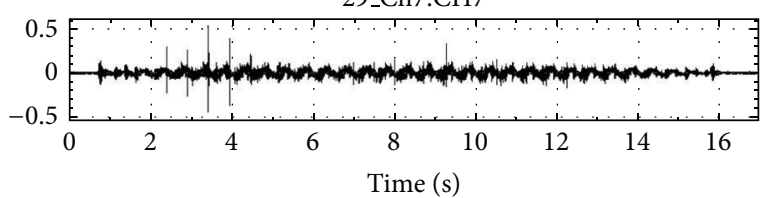

29_Ch8:CH8

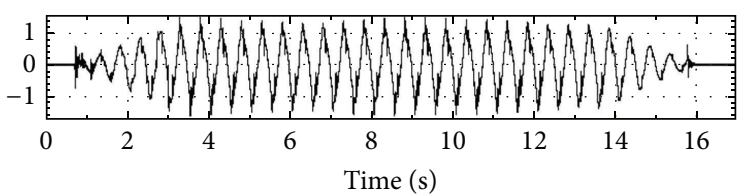

FIgURE 24: Microseism signals from different channels in working condition 29 ( $\mathrm{CH}$ indicates the sensors' serial numbers).

the vibration table and is not in accordance with the vibration response of an elastic system. We thus inferred that the specimen was no longer in the elastic deformation stage.

(4) Result at Input $0.75 \mathrm{~g}$ Peak Acceleration of Vibration. As shown in Figure 19, the enhancement coefficient declined as shock excitation frequency increased under $0.75 \mathrm{~g}$ acceleration input to the vibration table. The previous section allows us to conclude that the specimen's natural vibration in this condition was less than $20 \mathrm{~Hz}$. At this stage, shock excitation frequency varies considerably from natural frequency as it increases, and acceleration response decreases. Additionally, 

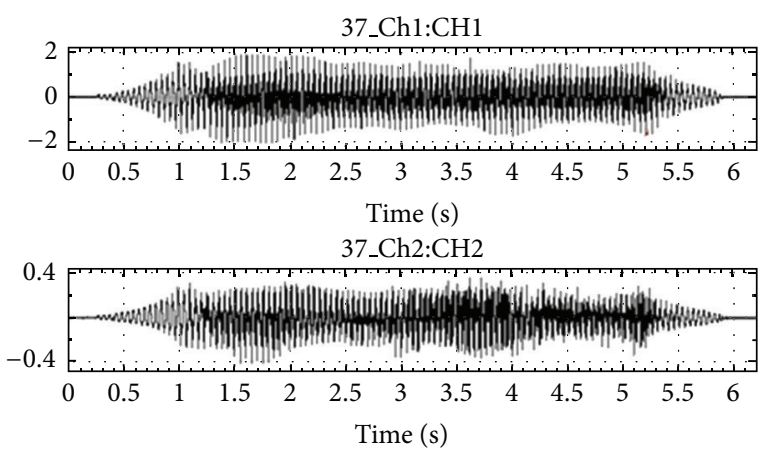

37_Ch3:CH3

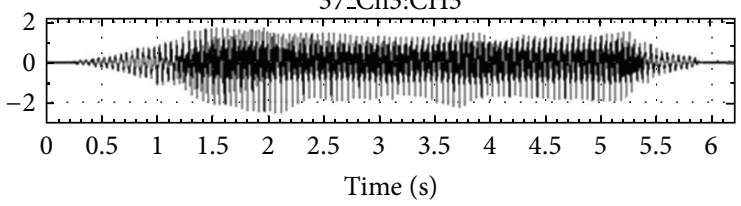

37_Ch4:CH4

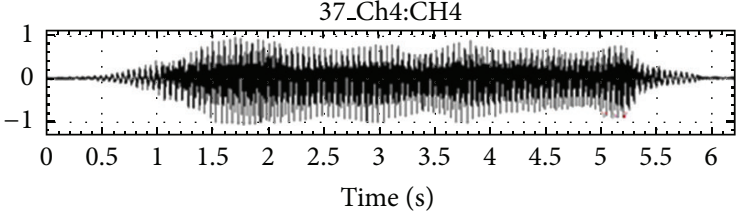

37_Ch6:CH6

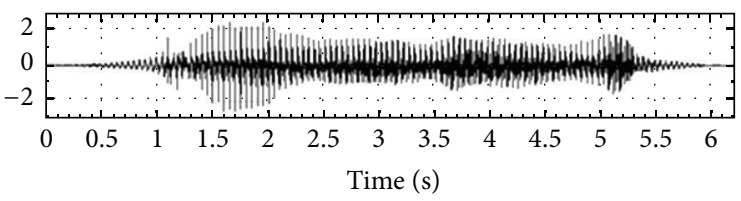

37_Ch7:CH7
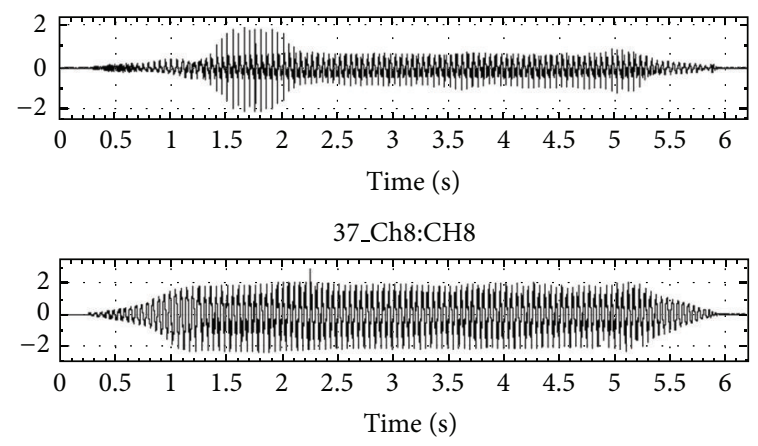

FIGURE 25: Microseism signals of working condition 37.

the $a 3$ value was not larger than $a 1$ or $a 2$, indicating the specimen was not in the elastic deformation stage.

(5) Result at Input $1.5 \mathrm{~g}$ Peak Acceleration of Vibration. Figure 20 shows enhancement coefficient curve of the acceleration response in this condition. When $1.5 \mathrm{~g}$ shock excitation acceleration was inputted to the vibration table, the microseismic signal amplitude enlarged and $a 2$ and $a 3$ remained high. As vibration continued, coal specimen fractures became more serious. Horizontal cracks appeared in many locations, the coal loosened, and coal particles began to drop out of the specimen (Figure 21). During this process, smoke was observed where the crack opened and closed.

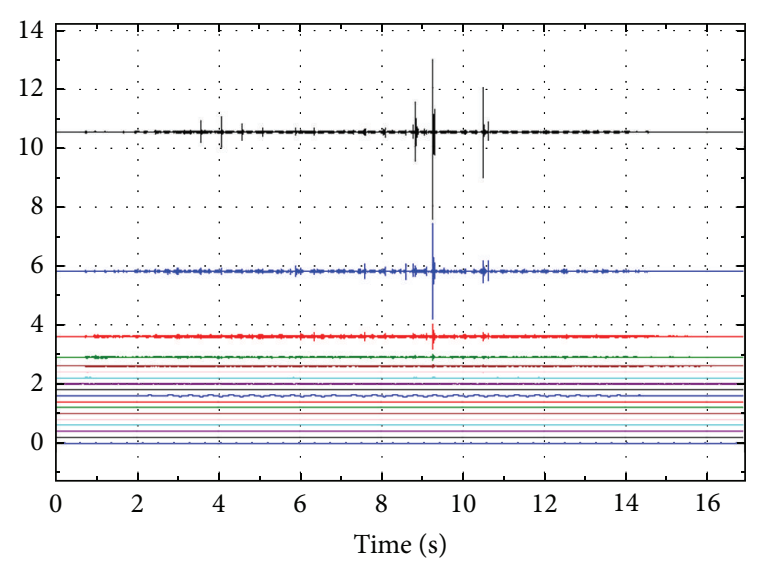

FIGURE 26: EEMD analysis results of original microseism signals from 4\# sensor in working condition 29.

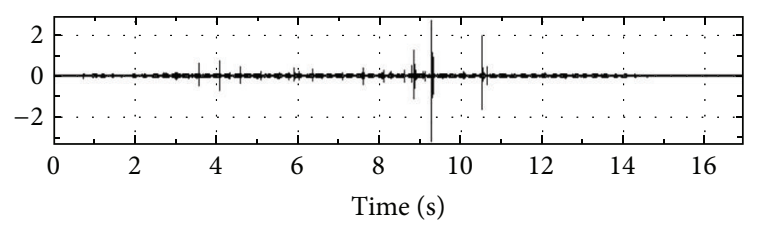

FIGURE 27: Effective microseism signals from 4\# sensor in condition 29.

TABLE 16: IMF component energy percentages of effective microseism signals by EEMD.

\begin{tabular}{lccc}
\hline IMF & $\begin{array}{c}\text { Working } \\
\text { components }\end{array}$ & $\begin{array}{c}\text { Working } \\
\text { condition } 43(\%)\end{array}$ & $\begin{array}{c}\text { Working } \\
\text { condition 53 (\%) }\end{array}$ \\
\hline condition 63 (\%) \\
IMF_h1 & 70.7 & 64.1 & 64.5 \\
IMF_h2 & 27.4 & 29.4 & 32.8 \\
IMF_h3 & 1.31 & 5.03 & 1.9 \\
IMF_h4 & 0.384 & 1.07 & 0.414 \\
IMF_h5 & 0.0921 & 0.207 & 0.157 \\
IMF_h6 & 0.0296 & 0.0651 & 0.0773 \\
IMF_h7 & 0.0149 & 0.0285 & 0.0465 \\
IMF_h8 & 0.00777 & 0.0172 & 0.027 \\
IMF_h9 & 0.00509 & 0.00983 & 0.0136 \\
IMF_h10 & 0.0021 & 0.00427 & 0.00626 \\
IMF_h11 & 0.00103 & 0.00192 & 0.00445 \\
IMF_h12 & 0.000539 & 0.000885 & 0.00212 \\
IMF_h13 & 0.000197 & 0.000562 & 0.000543 \\
IMF_h14 & 0.000227 & 0.000847 & 0.001 \\
IMF_h15 & $7.32 E-05$ & 0.000524 & 0.000759 \\
IMF_h16 & $6.79 E-06$ & $1.2 E-05$ & $9.34 E-05$ \\
\hline
\end{tabular}

Finally, when shock excitation acceleration reached $2.4 \mathrm{~g}$, severe destructive shaking occurred under shock excitation frequency of $5 \mathrm{~Hz}$. After the experiment, the steel frame was demolished. Damage was mainly concentrated in the coal seam (Figure 22). 


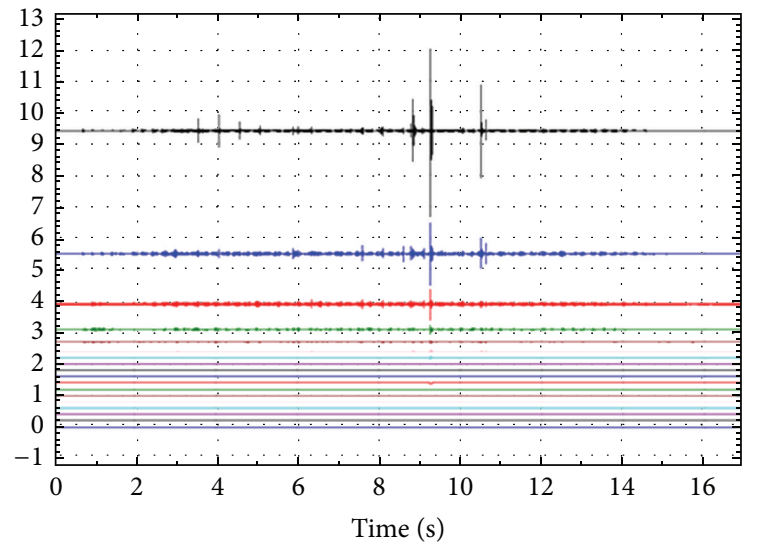

FIGURE 28: EEMD analysis results of effective microseism signals from $4 \#$ sensor in working condition 29.

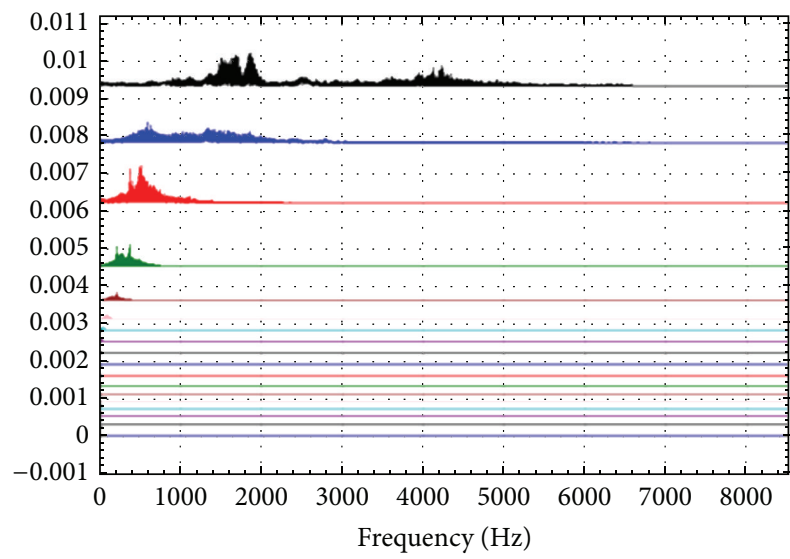

FIGURE 29: IMF components spectrum of effective microseism signals in working condition 29.

To summarize, the specimen stayed in the elastic deformation stage when the shock excitation acceleration peak was inputted at less than $0.5 \mathrm{~g}$. If the shock excitation acceleration peak was inputted beyond $0.5 \mathrm{~g}$, the specimen entered the inelastic deformation stage. Once shock excitation acceleration was determined, the shock excitation frequency's influence on acceleration response became obvious. When shock excitation frequency was close to the specimen's natural vibration, the acceleration response increased and a resonance phenomenon occurred once the shock excitation frequency and natural vibration were equal. During that time, the specimen grew prone to fracture due to the force of inertia.

5.2.2. Shock Excitation Acceleration Influence on Acceleration Response. To effectively study shock excitation acceleration peak influence on acceleration response, data measured under working conditions $7,19,39$, and 49 were selected for analysis. For this set of data, shock excitation frequency is $24 \mathrm{~Hz}$, and acceleration peaks are $0.02 \mathrm{~g}, 0.1 \mathrm{~g}, 0.5 \mathrm{~g}$, and $0.75 \mathrm{~g}$, respectively. The results are shown in Table 12 and Figure 23. Generally speaking, acceleration response

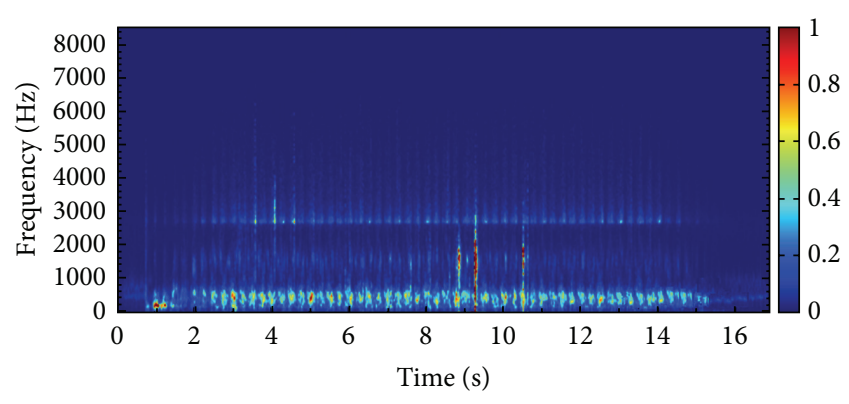

FIGURE 30: Hilbert energy spectrum of effective microseism signals in working condition 29.

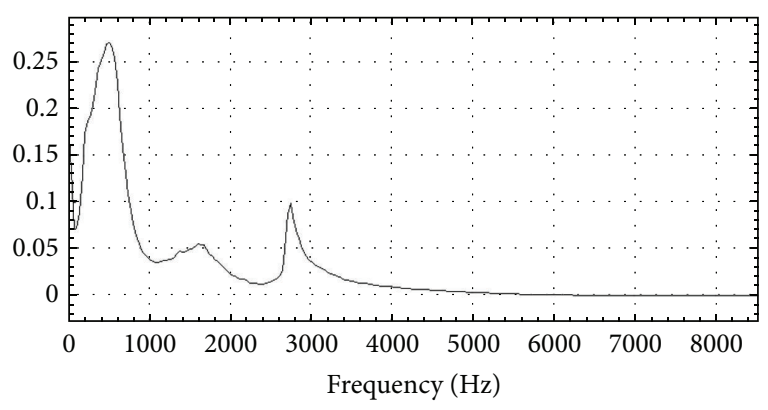

FIGURE 31: Hilbert marginal spectrum of effective microseism signals in working condition 29.

increases as shock excitation acceleration increases. Using the least square method, acceleration response data from $a 1$ (reflecting the vibration of the bottom of the specimen) meets fitting equation $y=1.1858 x+0.0388$ (where $x$ represents $a 0$ data reflecting shock excitation acceleration peak values,) and $R^{2}=0.9951$. Its law of change forms a linear relationship.

5.3. Microseism Signal Characters. Eight microseism signal sensors were installed in the specimen, detailed in Section 2. 1\#, 3\#, 5\#, and 8\# sensors measured microseism signals along the horizontal vibration direction, and 4\#, 6\#, and 7\# sensors measured microseism signals perpendicular to the vibration table. 2\# sensor sat atop the specimen. Sampling frequency was set to $17067 \mathrm{~Hz}$ for each working condition. Data from 5 \# sensor was discarded due to function failure.

5.3.1. Microseism Signal Characters at Specimen Start to Crack. Effective microseism signals began to appear in working condition 29, in which $0.5 \mathrm{~g}$ shock excitation acceleration and $2 \mathrm{~Hz}$ frequency were inputted to the vibration table, and vibration cycle was 30 .

Microseism signals were concentrated at $9 \mathrm{~s}-11 \mathrm{~s}$ from Figure 24. Signal amplitude from 1\#, 3\#, and 4\# sensors reached about 2.5, 0.6 from $2 \#$ and $6 \#$, and 0.5 from $7 \#$ and $8 \#$. This indicates that $1 \#, 3 \#$, and $4 \#$ sensors were close to the fracture location. When the direction of sensors matched the vibration direction, such as with $1 \#$ and $3 \#$, the signal from these sensors not only contained a high-frequency signal that caused the coal to burst, but also a low-frequency signal due 


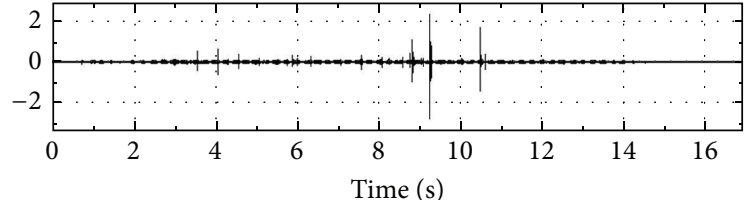

(a) Effective signals in working condition 29

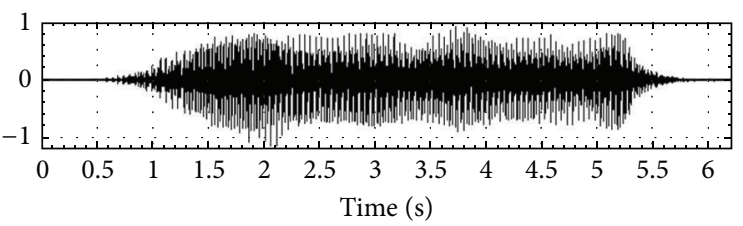

(c) Effective signals in working condition 37

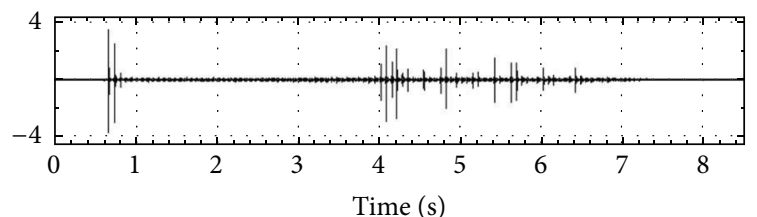

(b) Effective signals in working condition 35

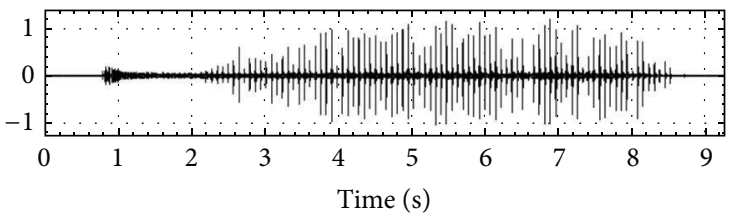

(d) Effective signals in working condition 41

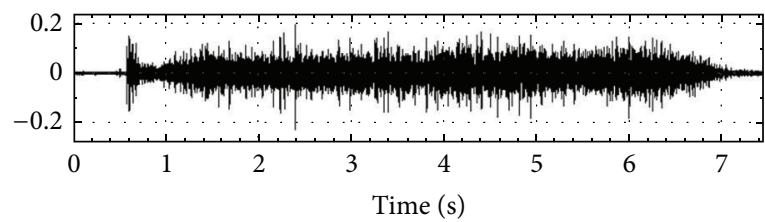

(e) Effective signals in working condition 47

FIGURE 32: Effective microseism signals for certain working conditions (4\# sensor).

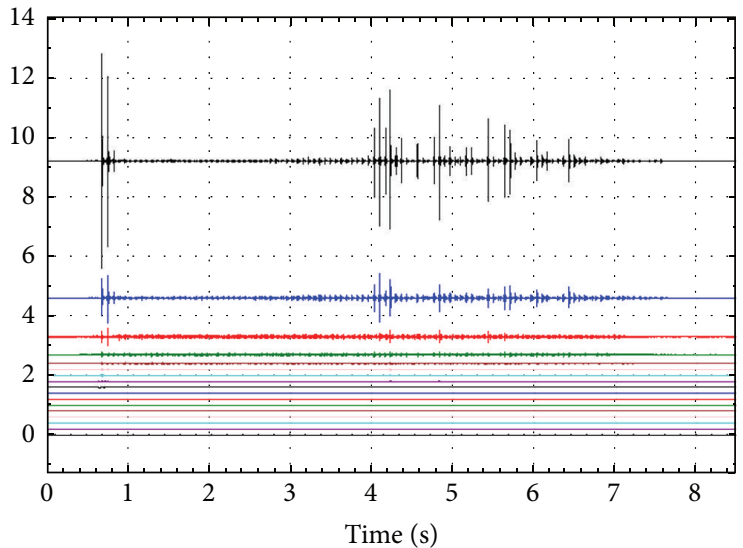

(a) IMF components

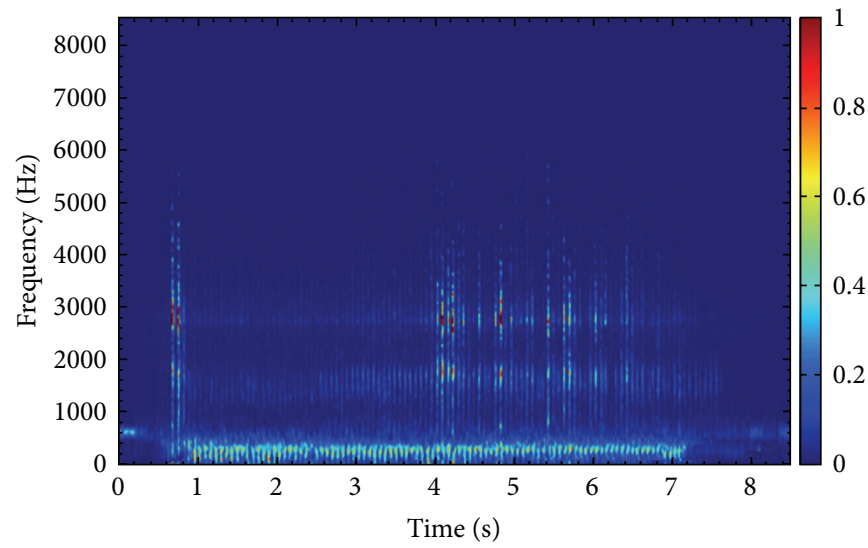

(c) Hilbert energy spectrum

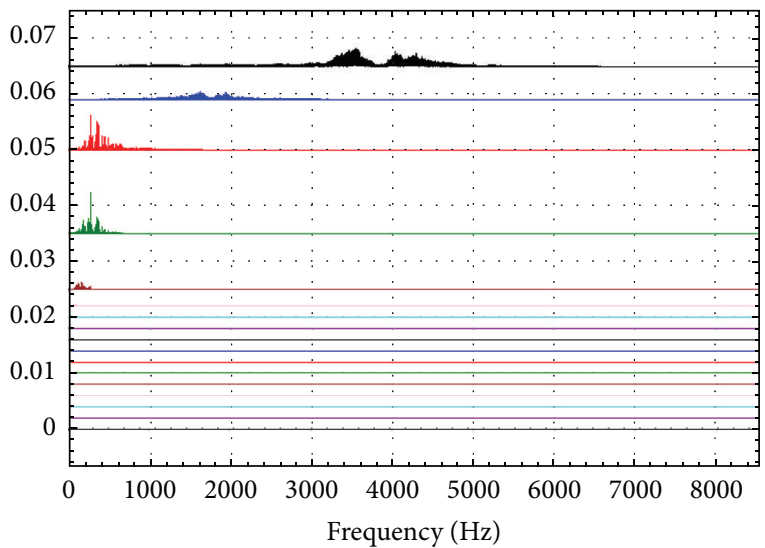

(b) IMF components spectrum

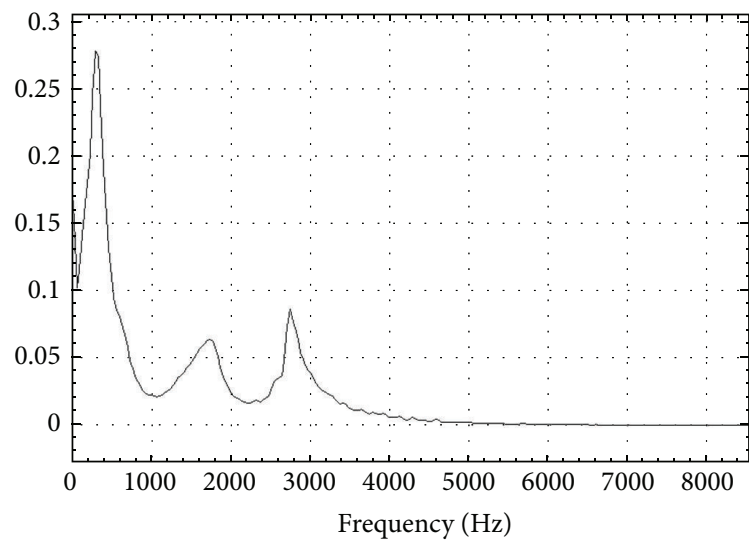

(d) Hilbert marginal spectrum

FIGURE 33: HHT analysis results in working condition 35. 


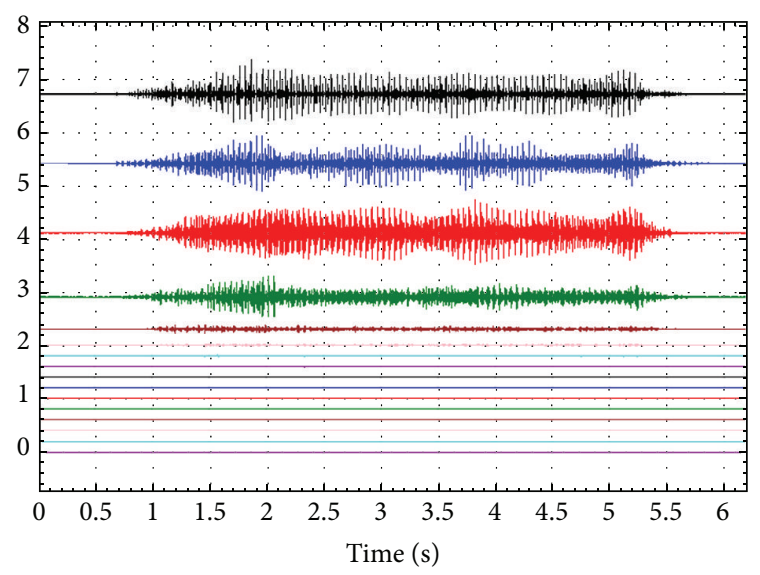

(a) IMF components

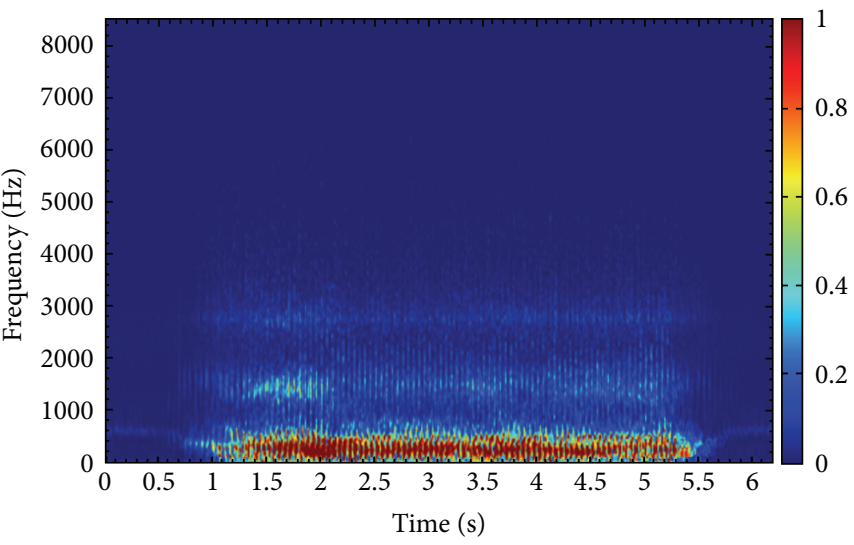

(c) Hilbert energy spectrum

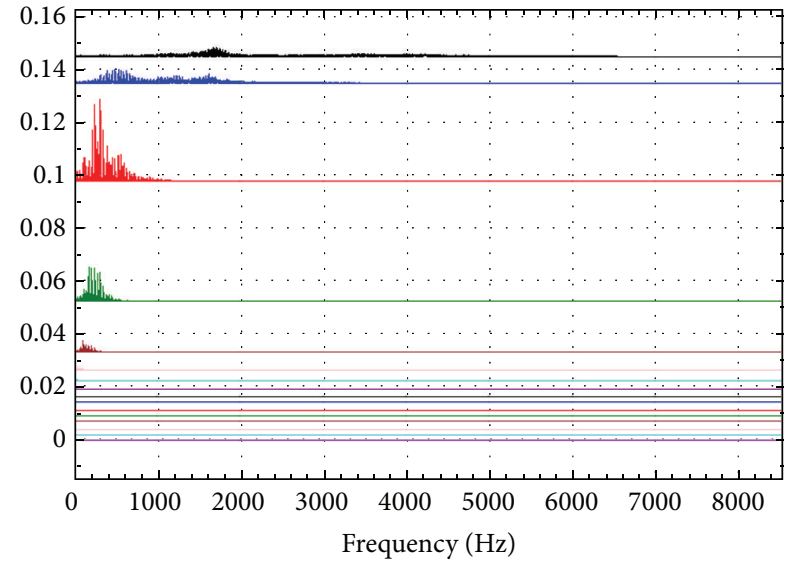

(b) IMF components spectrum

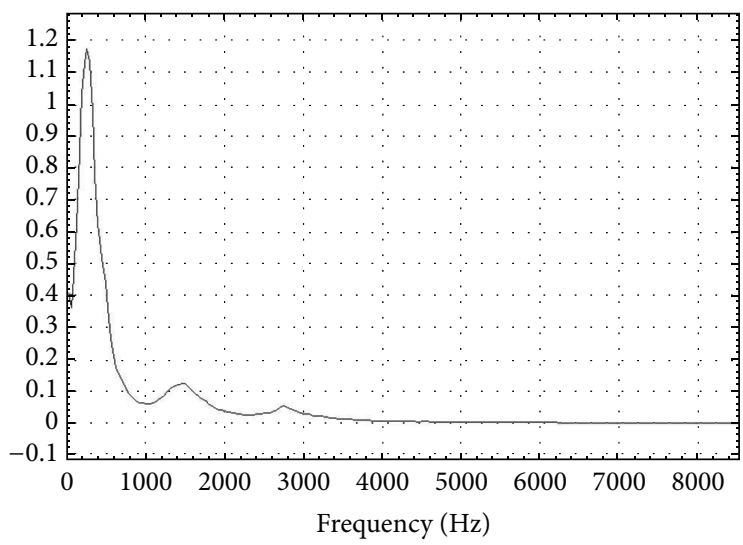

(d) Hilbert marginal spectrum

FIGURE 34: HHT analysis results in working condition 37.

to the specimen's vibration. These kinds of signals display the same characteristics as a carrier wave. Microseism signals from 1\#, 3\#, and 4\# sensors, perpendicular to the direction of vibration, also presented carrier signal characteristics, partially due to installation deviation. The $2 \#$ sensor was on top of the specimen quite far from the coal seam, so its signal amplitude was the smallest, as we concluded that destruction was mainly concentrated in the coal seam.

\subsubsection{Microseism Signal Characteristics When Resonance} Occurs. Resonance occurred in working condition 37, evidenced by analyzing acceleration response data. In this condition, a $0.5 \mathrm{~g}$ shock excitation acceleration and $20 \mathrm{~Hz}$ frequency were inputted to the vibration table, and the vibration cycle was 120. The specimen's natural vibration frequency matched the result from Chapter 5.1 (which measured white noise and a shock excitation acceleration of $0.02 \mathrm{~g}$ ) $42 \mathrm{~Hz}$. When shock excitation acceleration changed, the state of destruction in the specimen also changed, causing the natural vibration frequency of the specimen to fluctuate.

Figure 25 shows that the microseism signal in working condition 37 was greater than in working condition 29. This indicates that the number of fractures increased when resonance occurred. The acceleration response peak from the upper part of the specimen was bigger than the bottom. These signals also display carrier wave characteristics.

\subsubsection{Microseism Signal Analysis Using Hilbert-Huang Transform Method}

(1) Analyzing Microseism Signals in Working Condition 29 by Hilbert-Huang Transform Method. Hilbert-Huang transform (HHT) is a primary signal analysis method. By using the ensemble empirical mode decomposition (EEMD) method, it decomposes a signal into an intrinsic mode function (IMF). Instantaneous frequency data is also obtained though the Hilbert spectral analysis (HAS) method [20].

In working condition 29, the first original microseism signal appeared. The IMF component of the $4 \#$ sensor can be obtained by decomposing this original signal using the EEMD method. The following section aims to introduce the HHT method used in this experiment by processing microseism signal from the 4\# sensor.

The original microseism signal decomposed into 17 IMF components. Shown in Table 13 and Figure 26, the frequency decreased from IMF 1 to IMF 17. By processing every IMF 


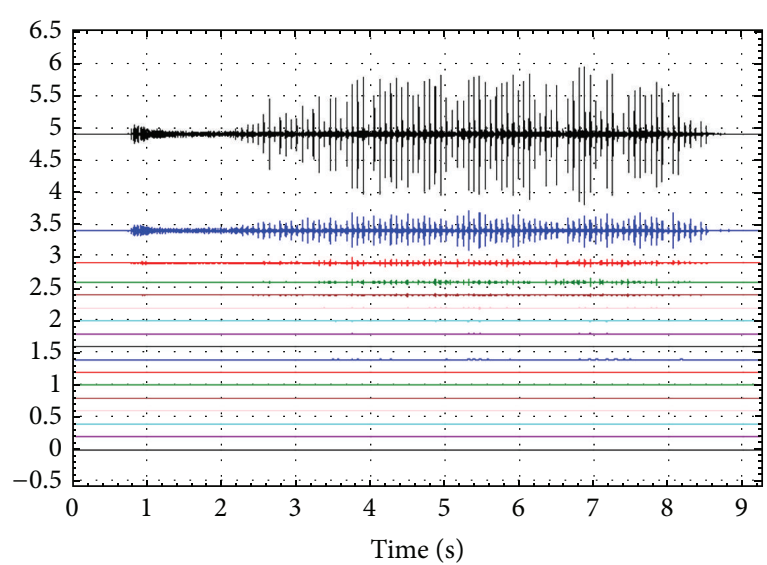

(a) IMF components

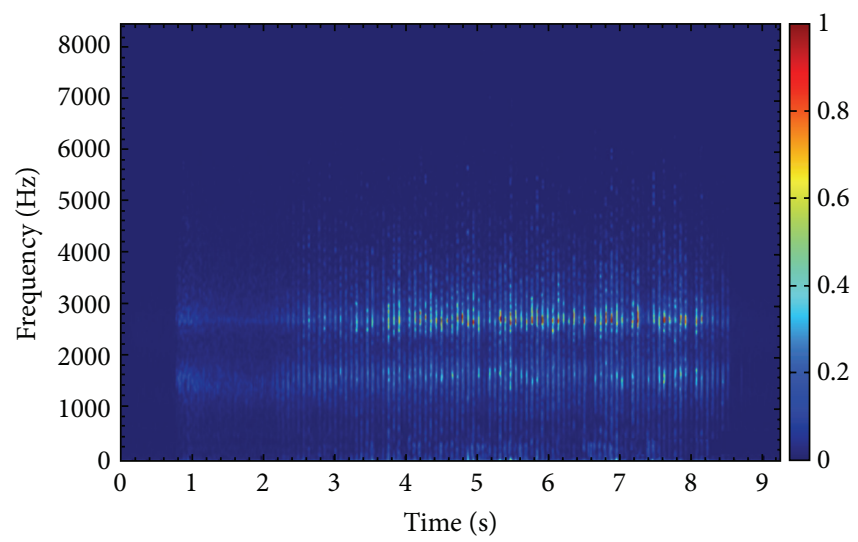

(c) Hilbert energy spectrum

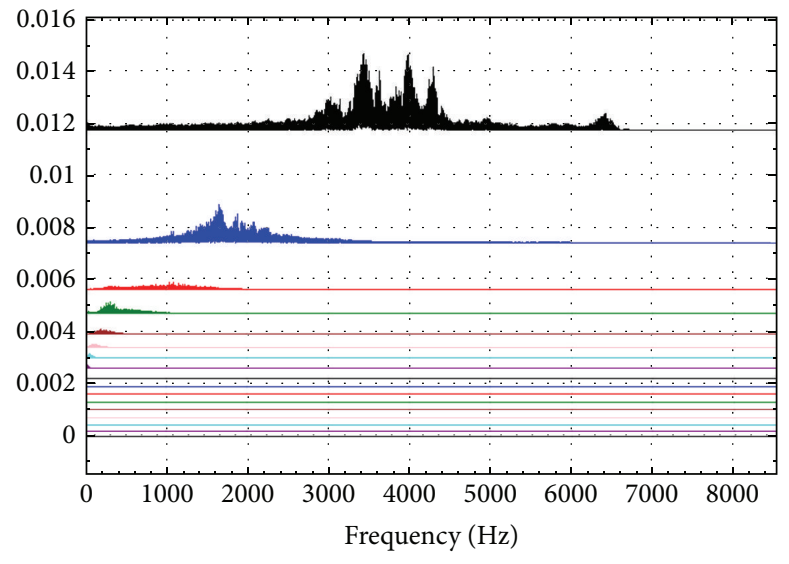

(b) IMF components spectrum

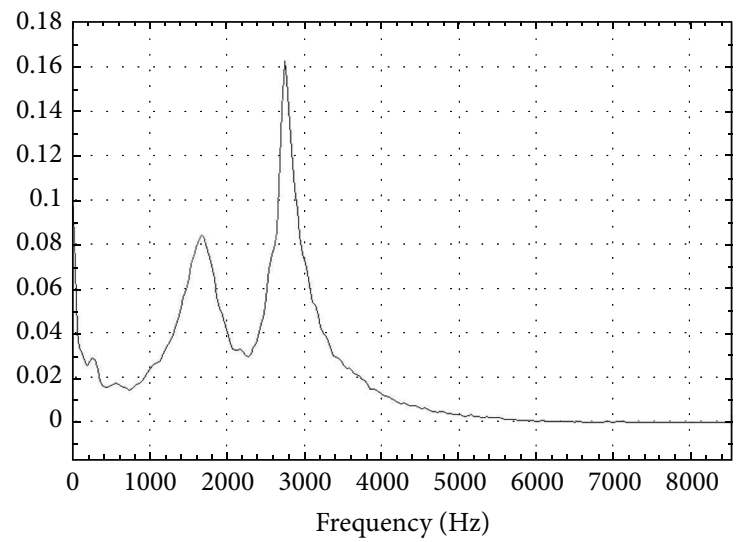

(d) Hilbert marginal spectrum

FIGURE 35: HHT analysis results in working condition 41.

component using the fast Fourier transform (FFT) method, we find that IMF 10, $2 \mathrm{~Hz}$, which accounted for $11.6 \%$ energy, is the sine signal caused by the vibration table's vibration due to input shock acceleration. IMF1-IMF4 components possess microseism signal characteristics of coal fracture and account for a considerable percentage of the energy. These IMF components are considered effective microseism signal components, and the other IMF components are attributed to environmental noise signals.

An effective microseism signal, shown in Figure 27, is composed of IMF1-IMF4 components and decomposed using the EEMD method.

17 new IMF components were obtained from the effective microseism signal (shown in Figure 28 and Table 14). The energy percentages of IMF1, IMF2, and IMF3 were far greater than any other components. These three components account for $96.6 \%$ of the energy, dominating the frequency of all components.

The FFT method was used to obtain spectra of IMF components. Shown in Figure 29, IMF1 has the widest range of frequency, from $1000-4500 \mathrm{~Hz}$. Its frequency is concentrated at $1000-2000 \mathrm{~Hz}$, and its peak appears at $1850 \mathrm{~Hz}$. The range of IMF2 is from 500 to $2000 \mathrm{~Hz}$, and its peak appears at
$600 \mathrm{~Hz}$. The IMF3 frequency range is $200-1000 \mathrm{~Hz}$ and peaks at $500 \mathrm{~Hz}$. In conclusion, the dominant frequency due to coal fracture is $200-4500 \mathrm{~Hz}$.

Hilbert energy spectrum and marginal spectrum are acquired by processing IMF components using Hilbert transform.

Figure 30 shows the relationship between frequency, time, and amplitude of effective microseism signals. In this figure, the deeper the color, the greater the energy. Energy is concentrated below $4000 \mathrm{~Hz}$. Instantaneous frequency in this figure fluctuates up and down around a center frequency, maintaining a large amplitude. This indicates that the microseism signal has a wide frequency range.

The Hilbert marginal spectrum (Figure 31) expresses the range of the global frequency, representing an accumulation of all amplitudes in the statistical view. This indicates the possibility for some frequencies to appear. The signal of the frequency between 500 and $4000 \mathrm{~Hz}$ is most likely to appear. 500,1700 , and $2470 \mathrm{~Hz}$ are the main frequencies.

In conclusion, effective microseism has a frequency range between 200 and $4200 \mathrm{~Hz}$ while main frequencies are 500, 1700 , and $2470 \mathrm{~Hz}$ under shock excitation acceleration $0.5 \mathrm{~g}$ and $2 \mathrm{~Hz}$ vibration input to the vibration table. 


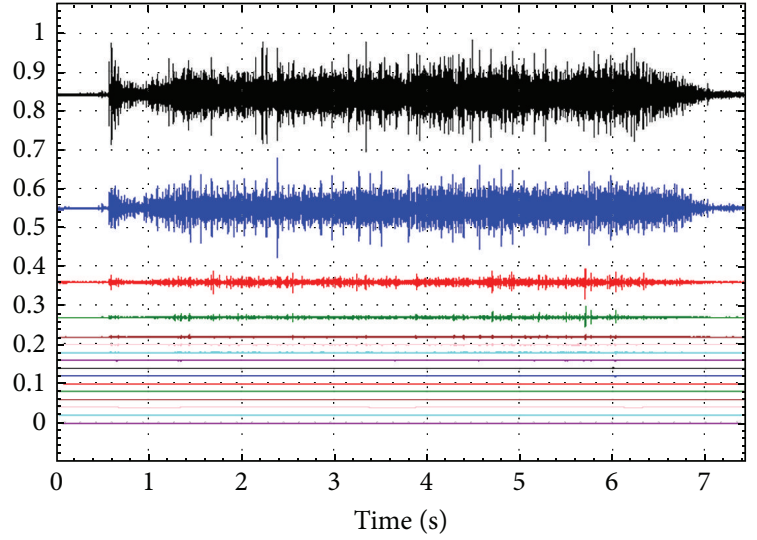

(a) IMF components

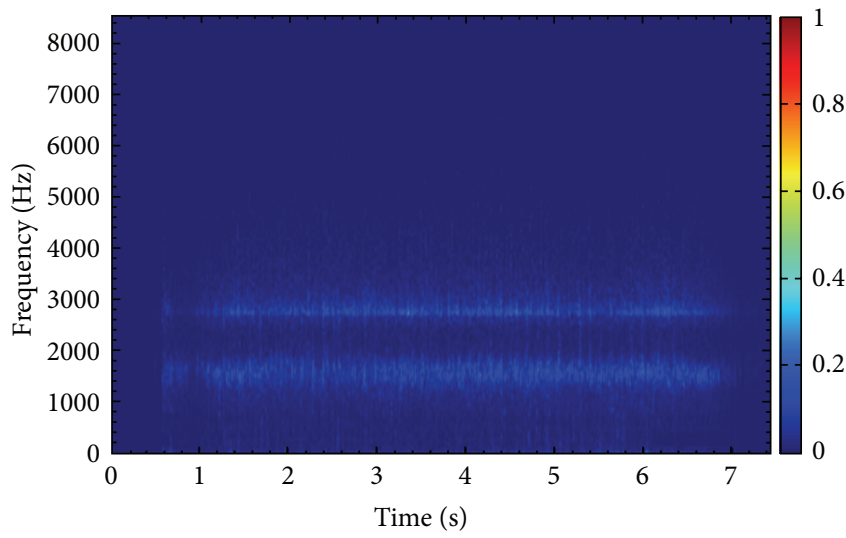

(c) Hilbert energy spectrum

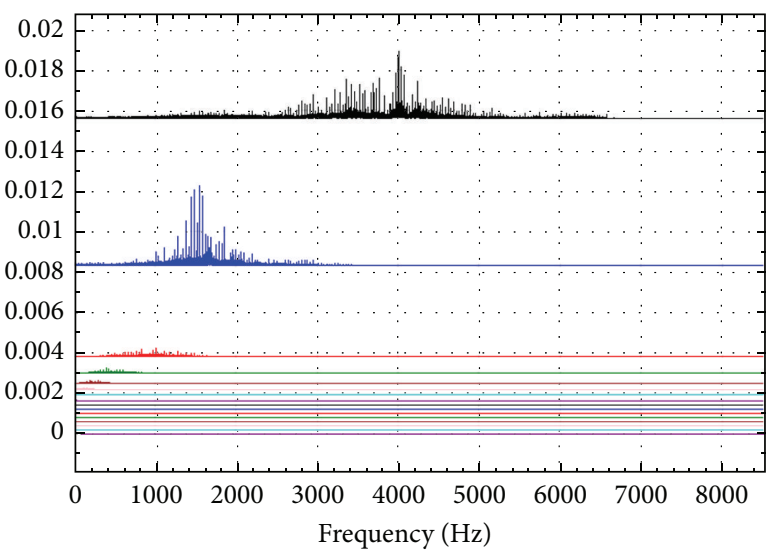

(b) IMF components spectrum

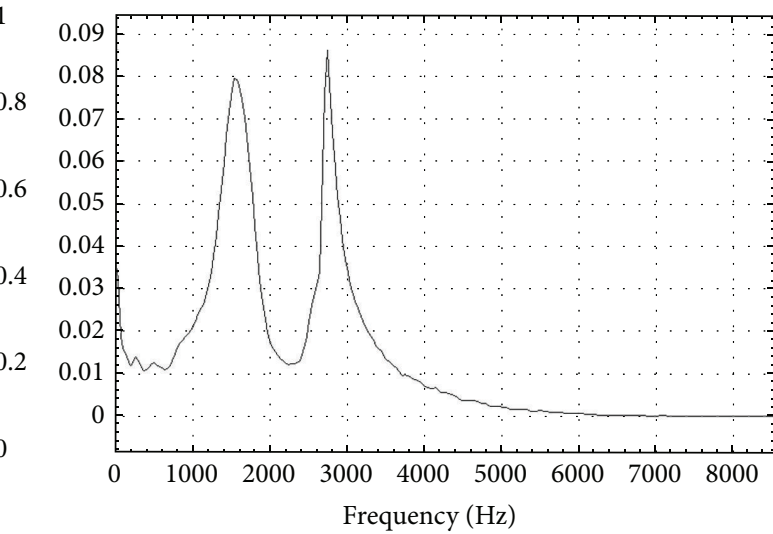

(d) Hilbert marginal spectrum

FIGURE 36: HHT analysis results in working condition 47.

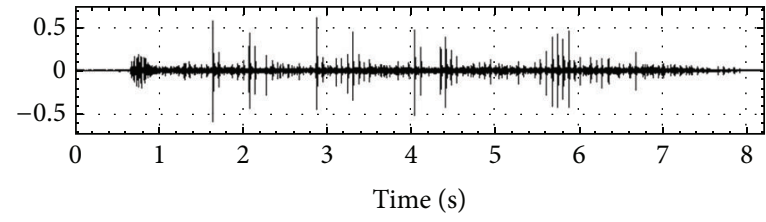

(a) Effective signals in working condition 43

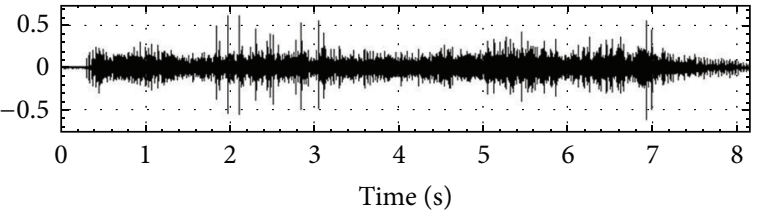

(b) Effective signals in working condition 53

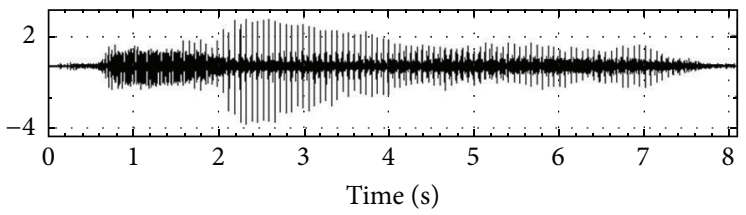

(c) Effective signals in working condition 63

FIGURE 37: Effective microseism signals in certain working conditions.

(2) Shock Excitation Frequency Influence on Microseism Signals. We selected $0.5 \mathrm{~g}$ shock excitation acceleration conditions to analyze shock excitation frequency's influence on microseism signals. Part analysis results are shown in Figures 32, 33, 34, 35, and 36 and Table 15. When input frequency is less than $20 \mathrm{~Hz}$, microseism is relatively sparse, and the amplitude of microseism signals varies widely. Maximum amplitude appears randomly. At a shock excitation frequency of $20 \mathrm{~Hz}$, microseism signals become very dense and amplitude increases. When shock excitation frequency is over $20 \mathrm{~Hz}$, the microseism signals become sparse again and amplitude decreases. Combining the results of Figure 18 


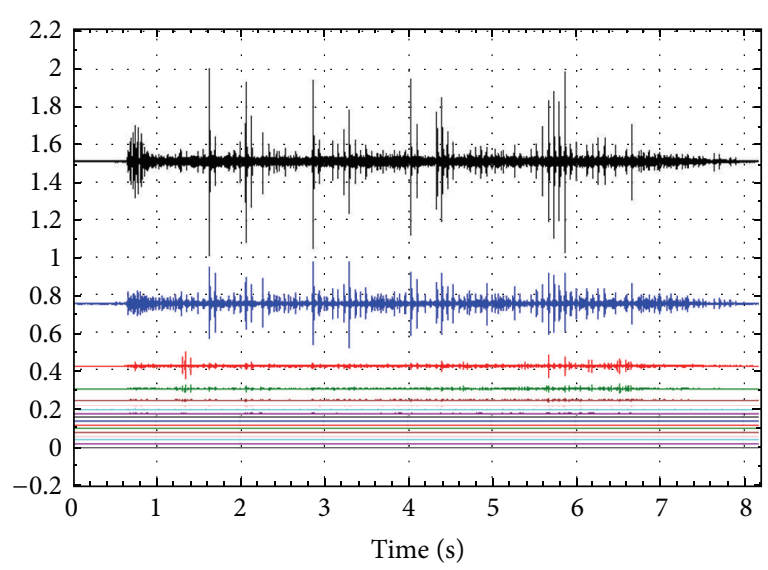

(a) IMF components

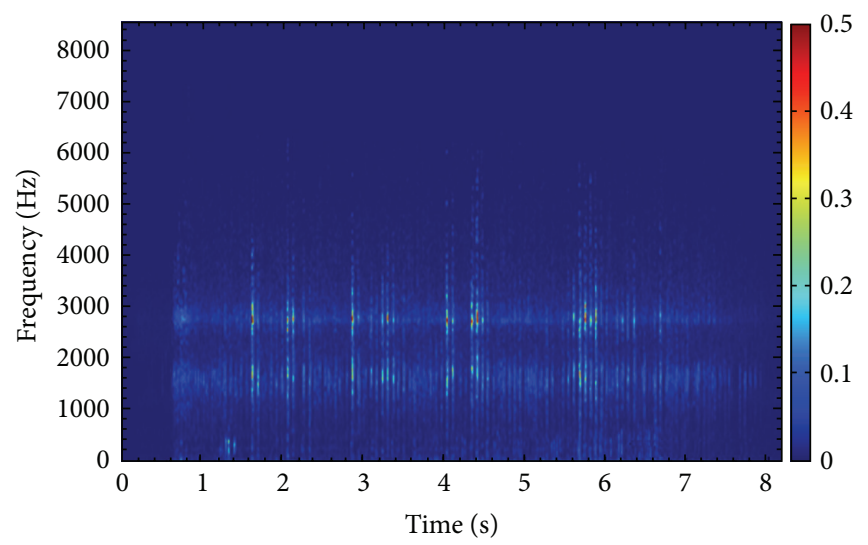

(c) Hilbert energy spectrum

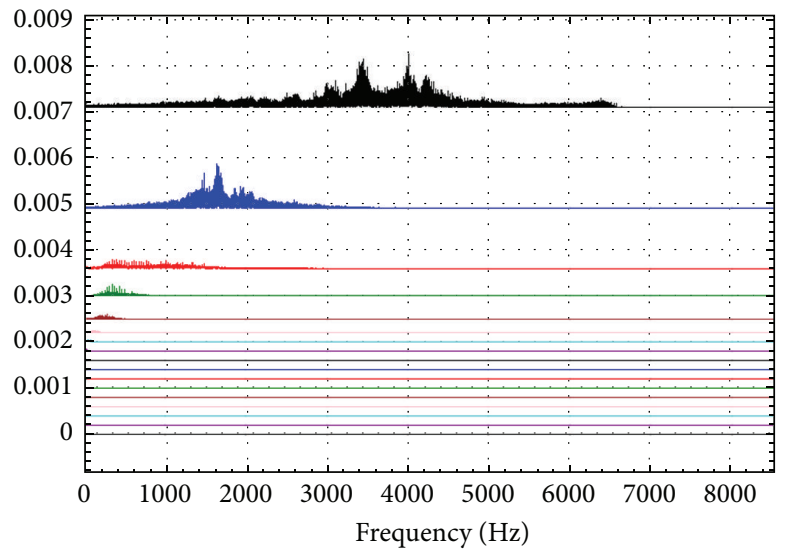

(b) IMF components spectrum

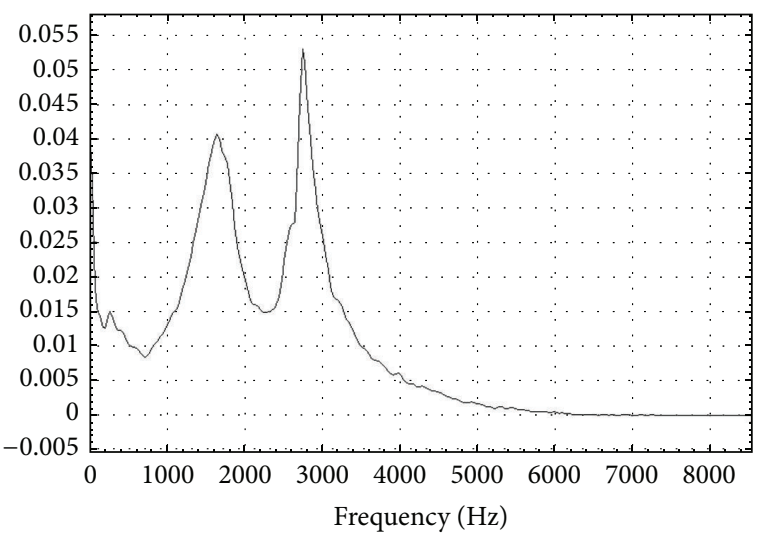

(d) Hilbert marginal spectrum

FIGURE 38: HHT analysis results of working condition 43.

result indicates that resonance has occurred, at which time the acceleration response peak reaches its maximum.

In working condition 37 (with a shock excitation frequency of $20 \mathrm{~Hz}$ ) the IMF3 component accounts for most of the energy percentage, where the frequency range is $200 \mathrm{~Hz}-$ $2000 \mathrm{~Hz}$ and the main frequencies are 300 and $1500 \mathrm{~Hz} .37$ differs from other working conditions in that IMF1 has the maximum energy percentage and a dominant microseism signal frequency range of $200 \mathrm{~Hz}-4500 \mathrm{~Hz}$ and 500,1700 , and $2740 \mathrm{~Hz}$ as main frequencies. The microseism signal frequency shifts from high to low likely due to the increased stress caused by inertia effect when resonance occurs.

In summary, shock excitation frequency has a clear influence on microseism signals. When shock excitation frequency is far from natural vibration frequency, coal fractures randomly occur once stress reaches a critical point. The specific cause of fractures or the amplitude of rupture duration time are unknown, demonstrating that microseism possesses the same characteristics. If shock excitation is close to natural vibration frequency, a large number of fractures are produced. Obvious microseism signals appear in every vibration cycle where frequency shifts lower.
(3) Shock Excitation Acceleration Influence on Microseism Signals. The previous section proved that the relationship between acceleration response and shock excitation acceleration peak changes from linear to nonlinear after the specimen cracks. This relationship affects microseism signals. Data from the 4\# sensor under working condition 43 (at a shock excitation peak of $0.5 \mathrm{~g}$ ) 53 (shock excitation peak $0.75 \mathrm{~g}$,) 63 (shock excitation peak $1.5 \mathrm{~g}$,) were selected to study shock excitation acceleration's influence on microseism signals. The frequency of these three working conditions was $30 \mathrm{~Hz}$. Figures 37 and 40 show HHT analysis results of the selected data.

As shown in Figure 37, sparse microseism appeared when shock excitation acceleration peak reached $0.5 \mathrm{~g}$ and amplitude 0.61. When shock excitation acceleration peak reached $0.75 \mathrm{~g}$, the number of small peak microseism signals increased while the microseism signals with larger amplitude remained sparse. The maximum amplitude in this situation was 0.62 . In working condition 63 , the shock excitation acceleration reached $1.5 \mathrm{~g}$, microseism increased significantly, and density was enhanced. The maximum amplitude was 3.08. We thus conclude that coal crack microseism signals 


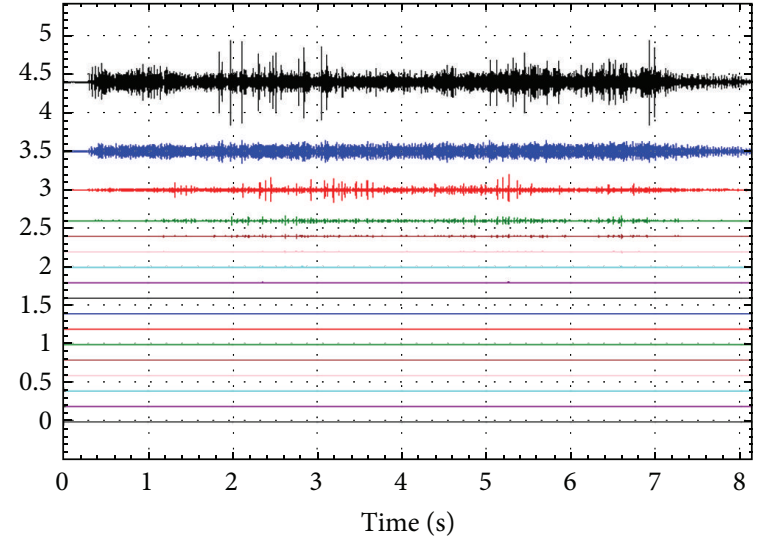

(a) IMF components

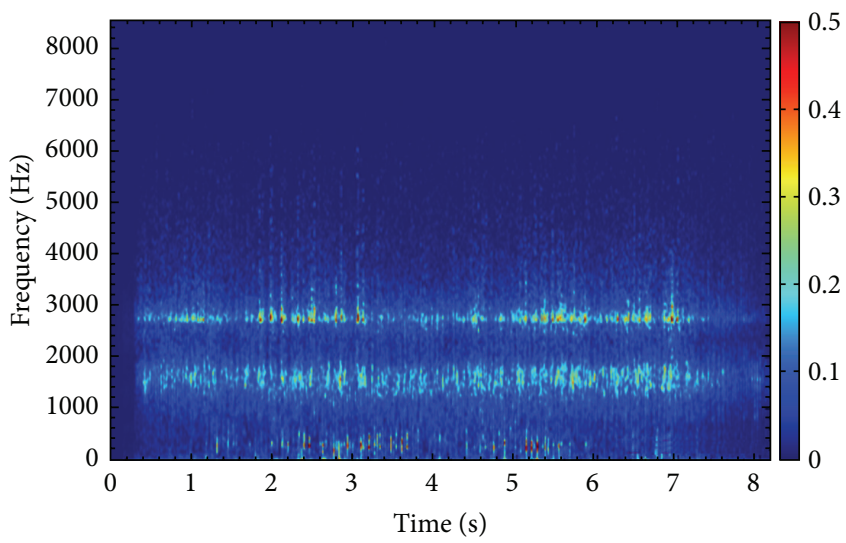

(c) Hilbert energy spectrum

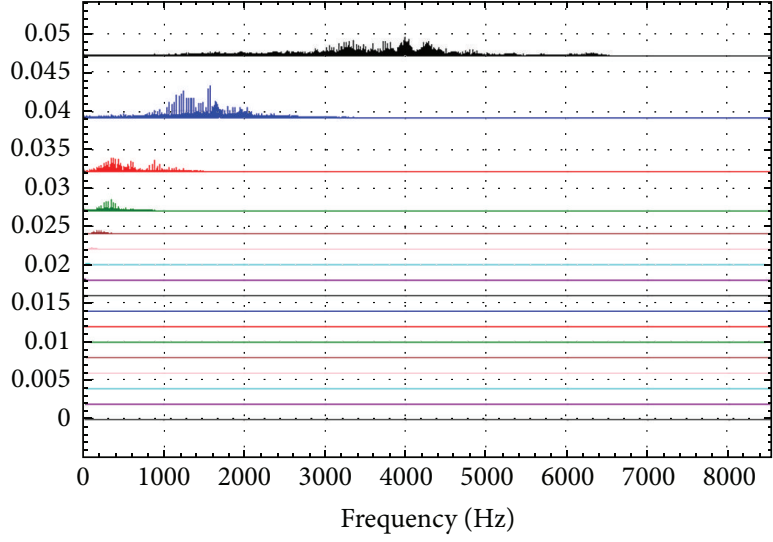

(b) IMF components spectrum

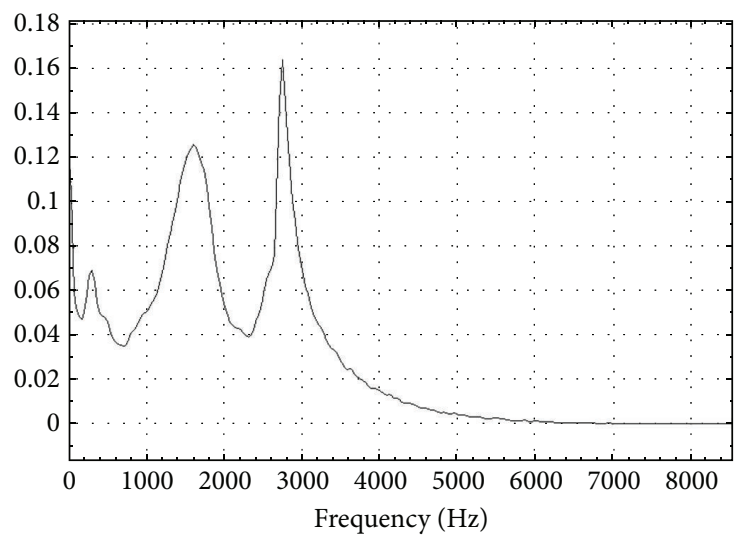

(d) Hilbert marginal spectrum

FIGURE 39: HHT analysis results of working condition 53.

amplitudes and number of fractures both increase as shock excitation acceleration peak increases.

From Figures 38, 39, and 40 and Table 16, it can be seen IMF1 and IMF2 are the main IMF components of effective microseism, and IMF1 accounts for the largest proportion of energy. As the shock excitation acceleration peak goes from $0.5,0.75 \mathrm{~g}$ to $1.5 \mathrm{~g}$, the frequency range also changes. IMF1 frequency range shifts from $3000 \mathrm{~Hz}-4000 \mathrm{~Hz}$ to $1000 \mathrm{~Hz}-$ $4000 \mathrm{~Hz}$, while IMF2 is unchanged. As evidenced by the IMF1 component, the microseism signal frequency range widens and the domain frequency shifts lower. Demonstrated by the Hilbert energy spectrum, microseism signal energy increases as shock excitation peaks incline. By forming an analysis which uses a combination of Hilbert energy spectrum and Hilbert marginal spectrum, we find that the instantaneous frequencies for these three signals are $1600 \mathrm{~Hz}$ or $2740 \mathrm{~Hz}$. An instantaneous frequency of $2740 \mathrm{~Hz}$ appears more often than $1600 \mathrm{~Hz}$ when shock excitation frequency is 0.5 or 0.75 and hardly at all when excitation frequency is $1.5 \mathrm{~g}$.

Based on these observations, we conclude that as shock acceleration and excitation peaks rise, the following phenomena occur: microseism signal density rises, amplitude enlarges, energy increases, number of fractures increases, dominant frequency shifts lower, and frequency range expands.

\section{Conclusion}

Vibration, which can cause coal destruction, reduce coal strength, and induce coal outbursts, is a very common phenomenon inherent to coal mining processes. When vibration occurs, energy signals such as microseism and EMR signals are generated and propagate. By receiving these signals and analyzing their characteristics, it is possible to evaluate damage and, ultimately, to dynamically predict disaster conditions.

Because of the complexity of geological conditions, it is difficult to simulate site environments accurately. In this paper, a simple experiment specimen was designed to effectively simulate a coal seam. A destruction situation within the specimen was simulated, and its microseism signal characteristics were gathered by acceleration and microseism sensor. The experimental data was then thoroughly analyzed. It was observed that, (1) with increased vibration, the specimen's natural frequency decreases and fractures begin to appear. (2) Shock excitation frequency significantly affected the coal 


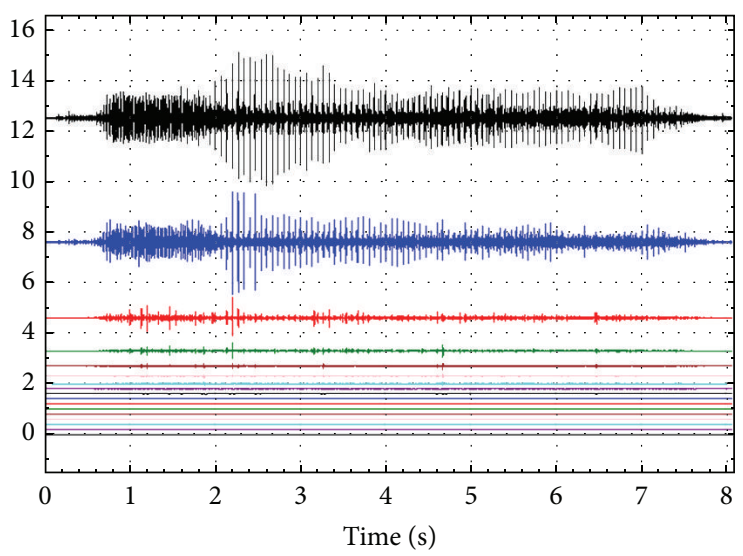

(a) IMF components

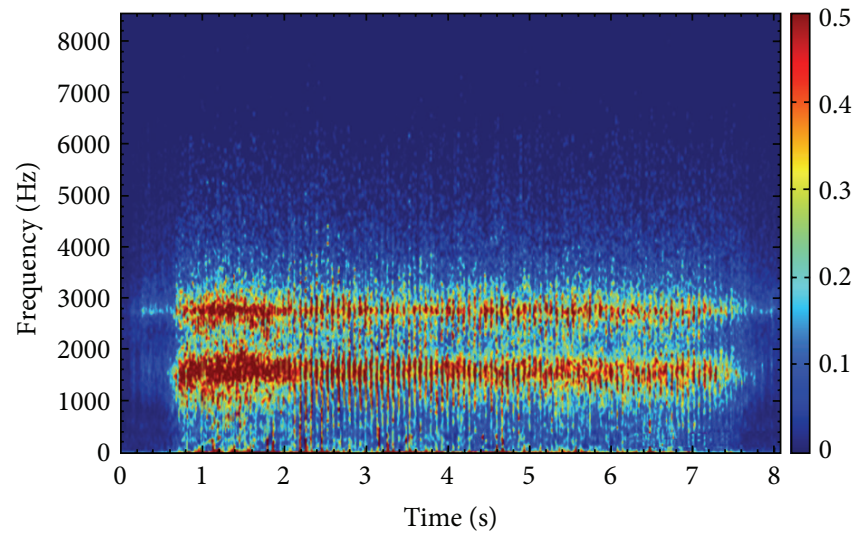

(c) Hilbert energy spectrum

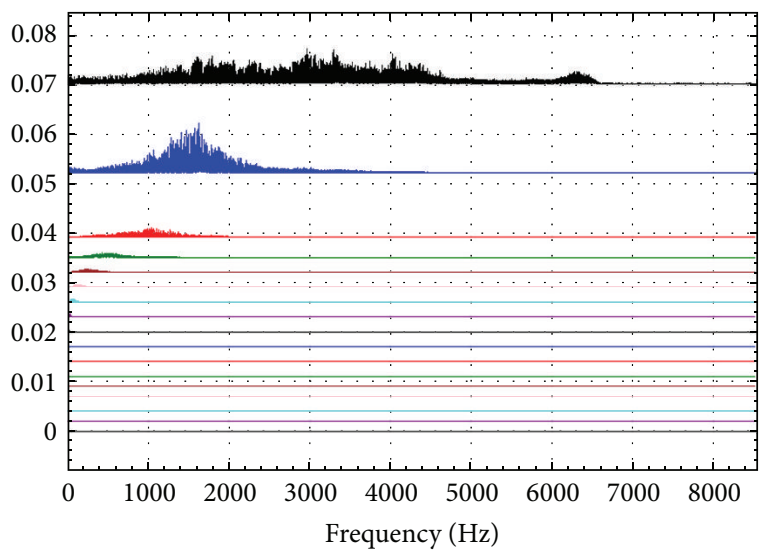

(b) IMF components spectrum

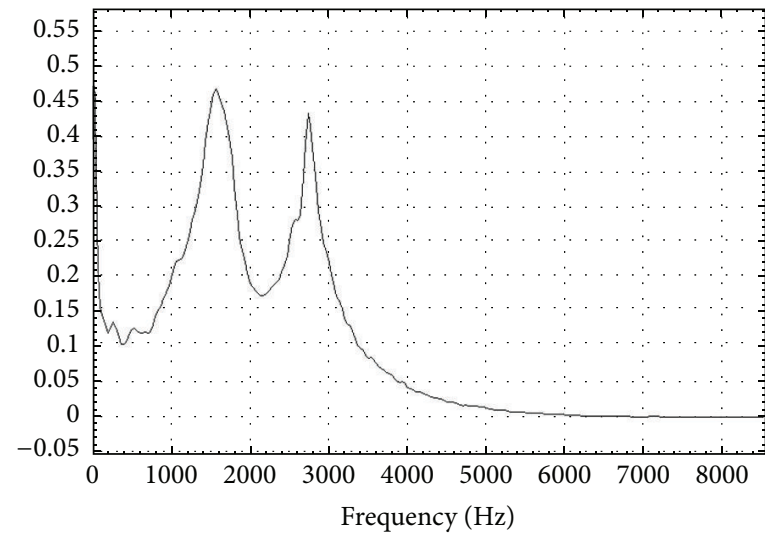

(d) Hilbert marginal spectrum

FIGURE 40: HHT analysis results of working condition 63.

specimen acceleration when the shock excitation acceleration peak remained unchanged. When shock excitation frequency nears the specimen's natural vibration frequency, the acceleration response peak increases and reaches its maximum when resonance occurs. (3) As shock excitation peak increases, the specimen's acceleration response peak also increases until the specimen enters an inelastic deformation stage. (4) When shock excitation acceleration is $0.5 \mathrm{~g}$ and input frequency is $2 \mathrm{~Hz}$, effective microseism signals in the frequency range $200-4200 \mathrm{~Hz}$ begin to appear, while the main frequencies are 500, 1700, and $2470 \mathrm{~Hz}$. (5) When shock vibration acceleration is $0.5 \mathrm{~g}$ and input frequency is less than $20 \mathrm{~Hz}$, microseism is relatively sparse. The microseism signals begin to vary wildly, and maximum amplitude appears at random. When shock excitation frequency is $20 \mathrm{~Hz}$, microseism signals become dense and amplitude increases. When shock excitation frequency is more than $20 \mathrm{~Hz}$, microseism signals become sparse again and amplitude decreases. (6) When the input frequency is $30 \mathrm{~Hz}$, microseism signal density rises, amplitude enlarges, energy increases, number of fractures grows, dominant frequency shifts low, and frequency range expands as shock acceleration and excitation acceleration peaks increase.
Notably, these results were all obtained in experimental conditions-in-site situations are more complex. In a real-life scenario, signals are affected by many other relevant factors, such as distance and varying vibration forms that would likely alter microseism signals significantly.

\section{Conflict of Interests}

The authors declare that there is no conflict of interests regarding the publication of this paper.

\section{Acknowledgments}

This research is supported by the National Natural Science Foundation of China (Grant no. 51274206) and Fundamental Research Funds for the Central Universities (Grant no. 2010YZ05). The authors would like to express their gratitude to these foundations.

\section{References}

[1] J. Shepherd, L. K. Rixon, and L. Griffiths, "Outbursts and geological structures in coal mines: a review," International Journal 
of Rock Mechanics and Mining Sciences and, vol. 18, no. 4, pp. 267-283, 1981.

[2] K. P. Chen, "A new mechanistic model for prediction of instantaneous coal outbursts-dedicated to the memory of Prof. Daniel D. Joseph," International Journal of Coal Geology, vol. 87, no. 2, pp. 72-79, 2011.

[3] A. J. Hargraves, "Instantaneous outbursts of coal and gas: a review," Proceedings-Australasian Institute of Mining and Metallurgy, no. 285, pp. 1-37, 1983.

[4] R. D. Lama and J. Bodziony, "Management of outburst in underground coal mines," International Journal of Coal Geology, vol. 35, no. 1-4, pp. 83-115, 1998.

[5] P. Guan, H. Wang, and Y. Zhang, "Mechanism of instantaneous coal outbursts," Geology, vol. 37, no. 10, pp. 915-918, 2009.

[6] Q. Yu and C. Jiang, "Spherical shell destabilization hypothesis of coal and gas outburst," Safety in Coal Mines, vol. 2, pp. 17-25, 1995.

[7] J. Litwiniszyn, "A model for the initiation of coal-gas outbursts," International Journal of Rock Mechanics and Mining Sciences \& Geomechanics Abstracts, vol. 22, no. 1, pp. 39-46, 1985.

[8] S. Zhou and X. He, "Rheological hypothesis of coal and methane outburst mechanism," Journal of China University of Mining \& Technology, vol. 19, no. 2, pp. 1-8, 1990.

[9] Y.-D. Jiang, Y.-X. Zhao, Y.-Q. Song, W.-G. Liu, and D.-J. Zhu, "Analysis of blasting tremor impact on roadway stability in coal mining," Chinese Journal of Rock Mechanics and Engineering, vol. 24, no. 17, pp. 3131-3136, 2005.

[10] X. He, B. Nie, W. Chen et al., "Research progress on electromagnetic radiation in gas-containing coal and rock fracture and its applications," Safety Science, vol. 50, no. 4, pp. 728-735, 2012.

[11] P. Styles, S. J. Emsley, and T. Jowitt, "Microseismic monitoring for the prediction of outbursts at Cynheidre Colliery, Dyfed, S. Wales," Geological Society Engineering Geology Special Publication, vol. 5, no. 1, pp. 423-433, 1988.

[12] V. Frid, "Electromagnetic radiation method for rock and gas outburst forecast," Journal of Applied Geophysics, vol. 38, no. 2, pp. 97-104, 1997.

[13] X. X. Shi, S. R. Cai, H. Feng, and H. Li, "The prediction of coal and gas outburst using the acoustic emission technique," Coal Geology \& Exploration, vol. 26, no. 3, pp. 60-65, 1998.

[14] X.-Q. He, E. Wang, and Z. Liu, "Experimental study on the electromagnetic radiation (EMR) during the fracture of coal or rock," in Proceedings of the International Symposium on Mining Science and Technology, pp. 133-136, Science Press, Beijing, China, 1999.

[15] V. Frid and K. Vozoff, "Electromagnetic radiation induced by mining rock failure," International Journal of Coal Geology, vol. 64, no. 1-2, pp. 57-65, 2005.

[16] S. Cao, Y. Liu, and L. Zhang, "Study on characteristics of acoustic emission in outburst coal," Chinese Journal of Rock Mechanics and Engineering, vol. 26, no. 1, pp. 2794-2799, 2007.

[17] C.-W. Li, W. Yang, S.-Y. Wei, T. Li, and L.-L. Chi, "Experimental research of influence scope of disaster gas after coal and gas outburst," Journal of China Coal Society, vol. 39, no. 3, pp. 478485, 2014.

[18] C. Wang, C. Li, J. Wang, P. Hu, Y. Cui, and X. Xu, "Characteristics of electromagnetic signals obtained during blasting rupture of coal in excavating workface," in Progress in Mine Safety Science and Engineering II, p. 63, CRC Press, 2014.

[19] B. Carter and R. Mancini, Op Amps for Everyone, Texas Instruments, 2009.
[20] Wikipedia, "Hilbert-Huang transform," 2010, http://en.wikipedia.org/wiki/Hilbert\%E2\%80\%93Huang_transform. 

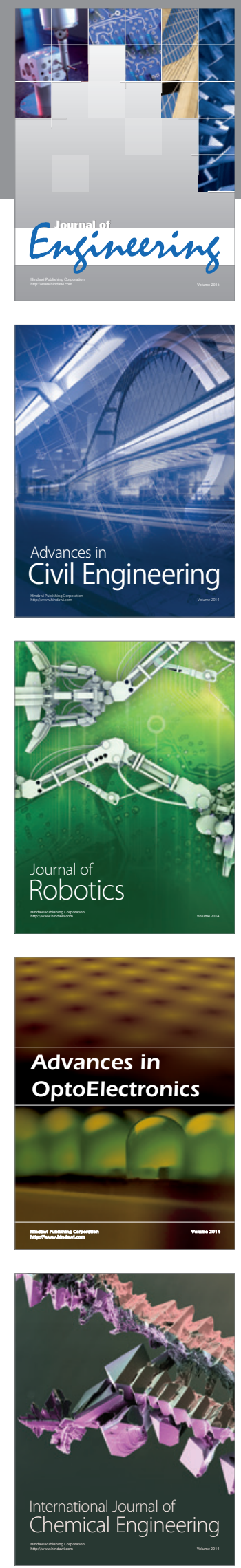

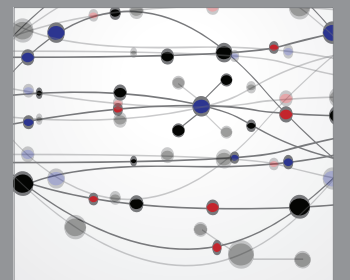

The Scientific World Journal
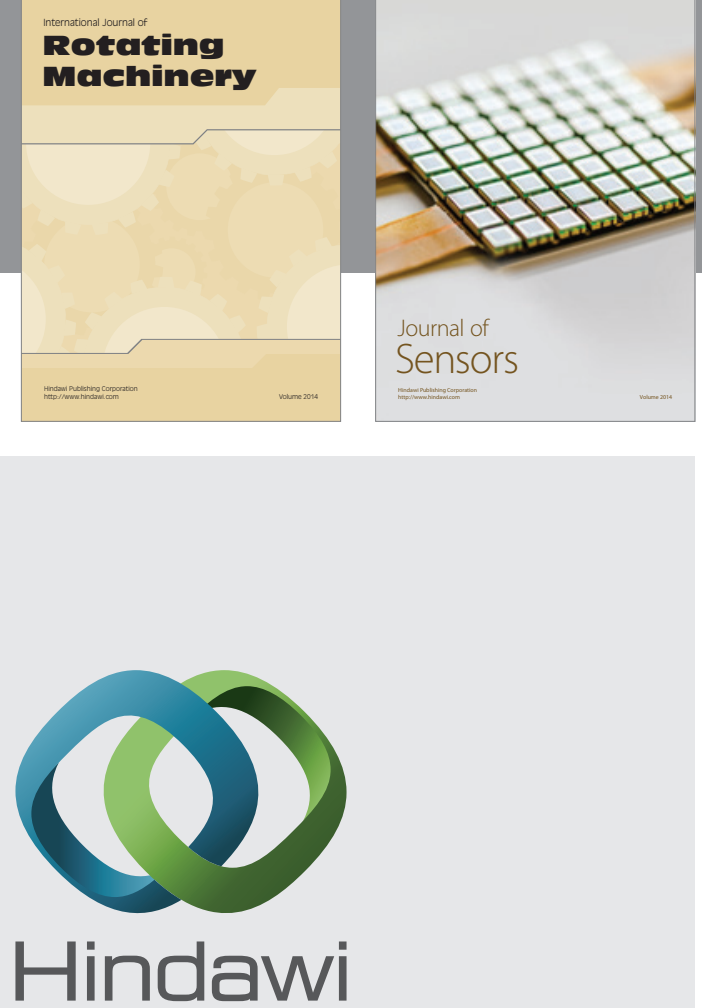

Submit your manuscripts at http://www.hindawi.com
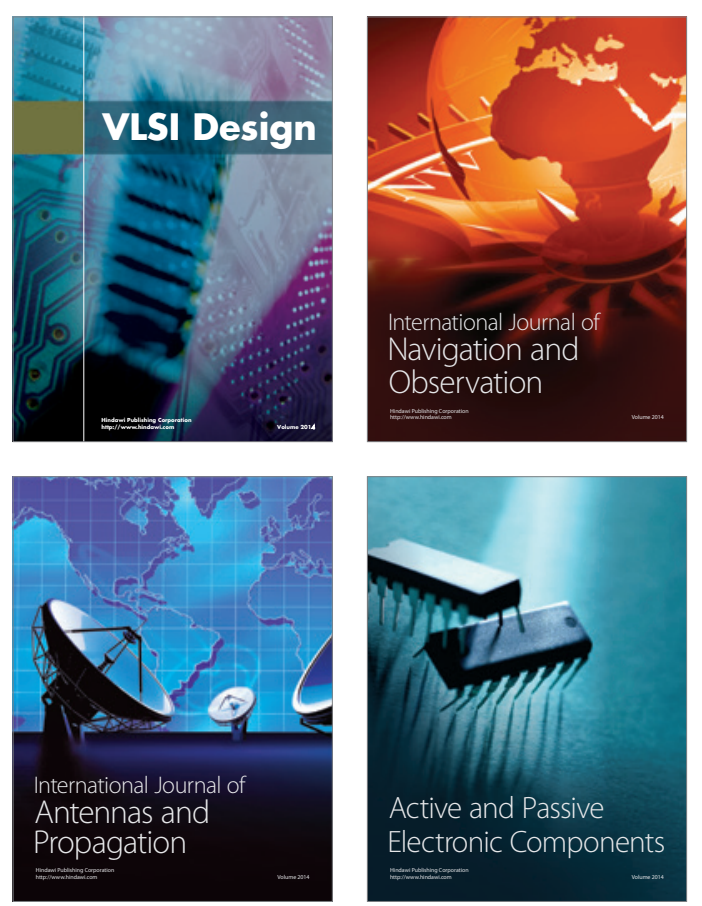
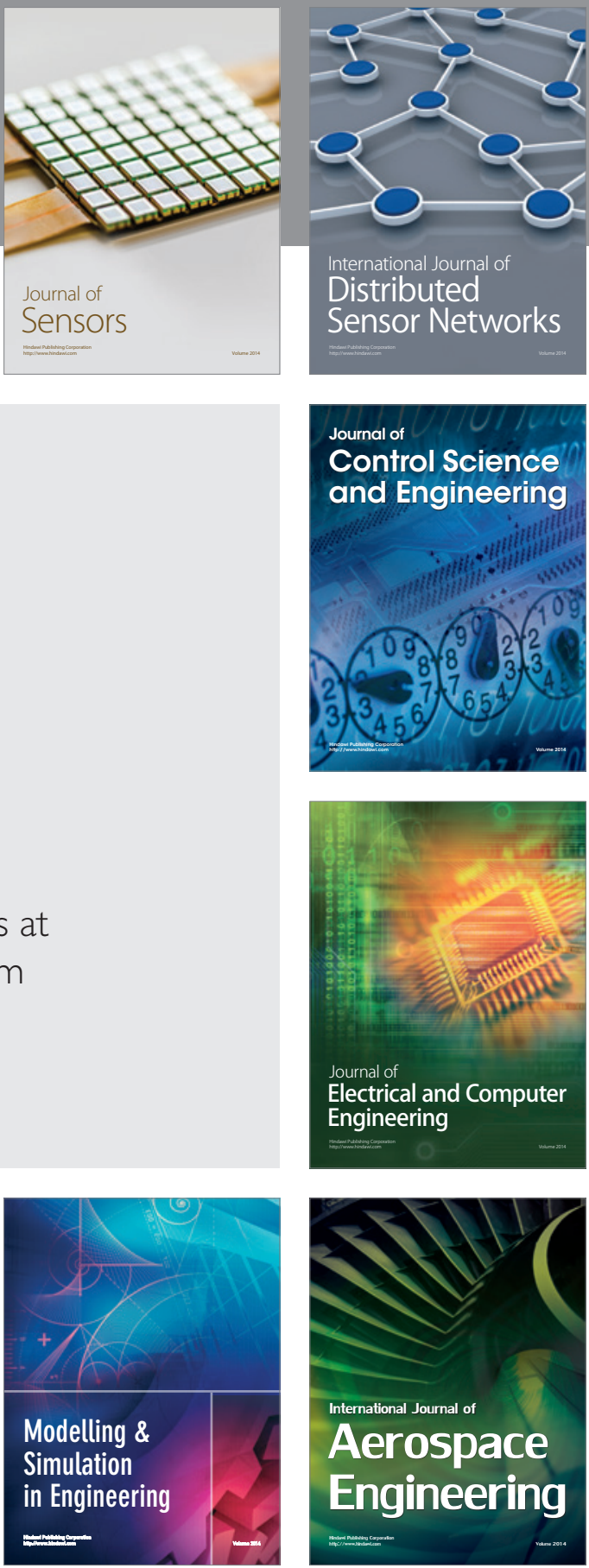

Journal of

Control Science

and Engineering
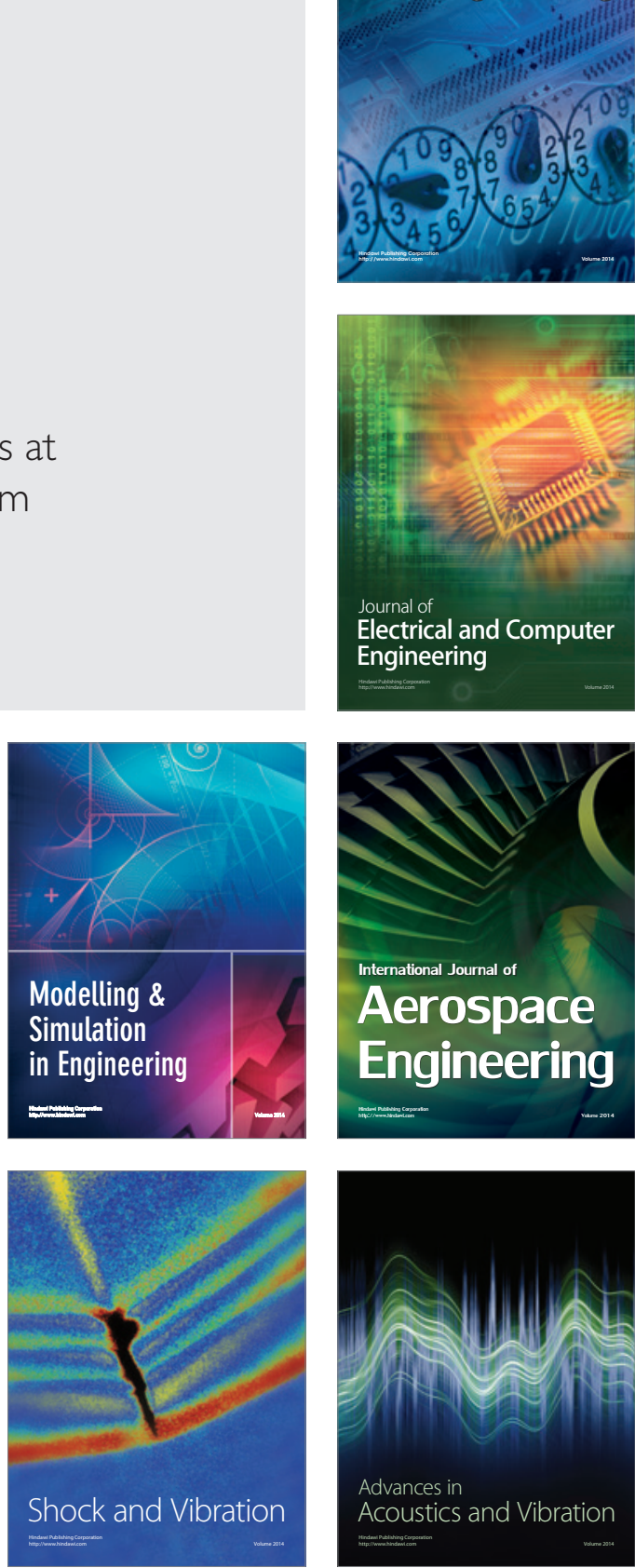